\title{
Visual Short-Term Memory of Stimulus Velocity in Patients with Unilateral Posterior Brain Damage
}

\author{
Mark W. Greenlee, Hans-Jörg Lang, Thomas Mergner, and Wolfgang Seeger \\ Neurologische Universitätsklinik and Neurochirurgische Universitätsklinik D-79104 Freiburg, Germany
}

Neurophysiological studies indicate the existence of an area in the extrastriate monkey cortex specialized for the processing of stimulus motion. The present investigation was conducted to determine whether a homologous area exits in the human cortex that underlies the processing and short-term storage of velocity information. Contrast detection and velocity discrimination thresholds were measured in a group of 23 patients with unilateral focal damage to either the lateral occipital, temporal, or posterior parietal cortex. Their results were compared to those of 23 agematched control subjects. Detection and discrimination thresholds were determined for spatially truncated sinewave gratings presented $4^{\circ}$ eccentric of fixation randomly in either the left and right visual fields. Contrast detection thresholds were measured in a spatial two-alternative forced-choice paradigm for three different drift rates $(1,2$, and $4 \mathrm{~Hz}$ ) for leftward and rightward drift directions. Simultaneous velocity discrimination thresholds were determined for reference and test gratings presented $4^{\circ}$ left and right of fixation. Sequential velocity discrimination thresholds were measured using a delay, with a interstimulus interval (ISIs) of 1,3 , and 10 sec. In a subset of five patients with superior temporal lobe damage, spatial frequency discrimination thresholds for stationary gratings were also determined. The results indicate the following: (1) contrast detection thresholds for drifting gratings did not significantly differ between the patient and control groups; (2) velocity discrimination thresholds were significantly elevated in the patients; (3) velocity discrimination thresholds significantly increased with increasing ISI in the patients; (4) velocity discrimination thresholds were elevated most when the patients had a lesion in the superior temporal cortex; (5) in the subgroup of five patients with superior temporal lobe damage, spatial frequency discrimination thresholds were not significantly elevated. The results suggest that there is a visual area in the human posterior tem-

\footnotetext{
Received Oct. 12, 1993; revised Sept. 26, 1994; accepted Sept. 28, 1994.

This research was supported by the Forschungsgemeinschaft (SFB 325, B4). M.W.G is a Feodor-Lynen Fellow of the Alexander von Humboldt Foundation (Bonn). Part of this work was used to fulfill the requirements for a medical degree at the University of Freiburg by H.J.L. We express our appreciation to the persons who served as subjects in the experiments and to Drs. L. Spillmann and $\mathrm{C}$. H. Lücking for their helpful comments. We gratefully acknowledge Dr. M. Soriano (Universitäts-Augenklinik) for performing acuity and visual perimetry measurements.

Correspondence should be addressed to Dr. Mark W. Greenlee, Neurologische Universitätsklinik, University of Freiburg, Hansastrasse 9, 79104 Freiburg, Germany.

Copyright $(\mathcal{C} 1995$ Society for Neuroscience $\quad 0270-6474 / 95 / 152287-14 \$ 05.00 / 0$
}

poral cortex that is involved in the processing and shortterm storage of the velocity of moving visual stimuli.

[Key words: velocity discrimination, human temporal cortex, visual short-term memory, contrast sensitivity, spatiotemporal vision, psychophysics]

The relative velocity and direction of targets moving in a visual environment are essential sources of information required to optimally plan and execute one's behavior. There is now considerable evidence that the primate brain contains extrastriate areas that are specialized in the processing of motion information. This evidence comes from anatomical (Spatz and Tigges, 1972; Spatz, 1977; Seltzer and Pandya, 1978; Ungerleider and Desimone, 1986; Boussaoud et al., 1990), neurophysiological (Maunsell and van Essen, 1983; Albright, 1984; Mikami et al., 1986a,b; Saito et al., 1986; Tanaka et al., 1986; Rodman and Albright, 1987; Snowden et al., 1992), and behavioral studies (Newsome et al., 1985; Newsome and Paré, 1988) in monkey brain. Selective destruction of pathways from parvo- and magnocellular laminae of the lateral geniculate nucleus in the thalamus suggest that, already at early stages of visual processing, information about the form and color of visual stimuli might be separated from information about motion and flicker (Maunsell et al., 1990; Schiller et al., 1990; Merigan et al., 1991). This evidence has led to the suggestion that information about stimulus form might follow a more ventral path from visual striate to inferotemporal cortex, whereas information about stimulus location and velocity might be processed along a more dorsal path, extending from the visual striate cortex, to the superio-temporal and parietal cortex (Ungerleider and Mishkin, 1982; Livingston and Hubel, 1987, 1988). Although such dichotomies cannot adequately reflect the complexity of visual encoding in primate brain, they do suggest the existence of separate extrastriate areas specialized in the processing of the form and color or the location and velocity of visual stimuli (Zeki, 1971, 1978). Cells have been found in the areas MT and MST in the bank and fundus of the macaque superior temporal sulcus, which selectively respond to ecologically relevant forms of stimulus motion (Tanaka et al., 1989; Tanaka and Saito, 1989). The direction selectivity of these cells appears, for the most part, to be invariant to stimulus features carrying the motion signals (Albright, 1992). These areas have also been implicated in the processes underlying smooth pursuit eye movements (Komatsu and Wurtz, 1988a,b; Newsome et al., 1988). Accurate encoding of stimulus motion alone would, however, be insufficient for an organism to adequately plan and execute its bchavior. Visually guided behavior demands, in addition to accurate coding, the short-term storage of stimulus motion information, as well as the instantaneous retrieval of this information from memory. 
In humans, evidence is now accumulating from positron emission tomography (Corbetta et al., 1991; Zeki et al., 1991) and functional magnetic resonance imaging (Kwong et al., 1993; Tootell et al., 1993) that indicate that there is an extrastriate drea in the border region of the occipital and temporal cortex that is involved in the processing of the direction and speed (i.e., velocity) of moving stimuli. Neuropsychological studies of patients with bilateral or unilateral posterior brain damage suggest the existence an analogous area in the extrastriate human cortex that subserves the processing of image motion (Zihl et al., 1983, 1991; Newcombe et al., 1987; Vaina, 1989; Plant et al., 1993). Healthy human observers can correctly discriminate small differences in the velocity of moving targets (Notterman and Page, 1957; Brandalise and Gottsdanker, 1959; Mandriota et al., 1962; McKee, 1981; Orban et al., 1984), and this precision can be maintained despite random variations in the contrast and spatial frequency of the grating stimuli (McKee et al., 1986). In addition, stimulus velocity can also be stored in visual short-term memory for durations up to $10 \mathrm{sec}$ without loss of precision (Magnusscn and Grcenlec, 1992). A similar precision in visual short-term memory has been demonstrated for information about the spatial frequency of stationary grating stimuli (Magnussen et al., 1990, 1991), suggesting the possible existence of specialpurpose memory mechanisms for such basic visual stimulus dimensions (Magnussen et al., 1995).

In the present investigation we have explored the simultaneous and sequential discrimination of the speed of drifting sinewave gratings in patients with focal, unilateral damage to the temporal, lateral occipital, and posterior parietal cortex. Contrast detection and velocity discrimination thresholds were determined for eccentrically presented sinewave grating patches. The results indicate that contrast detection thresholds for drifting gratings do not differ between patient and control groups. Speed discrimination for simultaneously presented stimuli are also within the normal range for most of these patients. Contrary to these results, the discrimination thresholds for sequentially presented stimuli are significantly elevated in patients with lesions in the posterior temporal cortex. Five of the patients, who exhibited elevated speed discrimination thresholds, were retested for their ability to discriminate the spatial frequency of stationary gratings. Their performance on this task did not significantly differ from that of five control subjects, suggesting that the deficit is specific to the processing of stimulus velocity.

\section{Materials and Methods}

Patients and control subjects. The observers were 23 former patients who showed objective signs of focal cortical lesion in one of the cerebral hemispheres. Table 1 presents the most relevant clinical data on the patient sample. The patients were selected from the medical archives of the Department of Neurosurgery of the University of Freiburg. They were recruited with informed consent after consulting their general practitioner or neurologist. The patient group consisted of 12 females and 11 males. Three of the patients were left handed. The exclusion criteria were as follows: age $>70$ years, more than one cerebral lesion, lesions located-in the hippocampus or rhinal and perirhinal cortex (areas known to be involved in general human memory), glioblastoma or metastases, an ill-defined lesion (e.g., edema), signs of visual neglect in the case history, pronounced neuropsychological disorders, radiation therapy, on-going high-dose medication therapy with potentially sedating drugs and/or drug intoxication. All subjects performed a neuropsychological test of general memory, which was the Corsi block tapping test, and were excluded if their score was $<4$ (see below). Table 1 presents a description of the patient group. Twenty-two patients had undergone surgical resection of a vascular malformation or a tumor, the malignancy of which did not exceed WHO II (4 astrocytomas, 1 meningioma, 2 oligoastrocytomas, and 15 cavernomas-angiomas). One patient (PAT18) had a well-defined ischenic lesion. All lesions were located in or near the cortical gray matter. The patients were studied, on average, 28 months following surgery (the range was 2 to 78 months). Fourteen patients had damage in the left cerebral hemisphere (PAT01 to PAT14) and 9 had a lesion in the right hemisphere (PAT15 to PAT23, see below). The lesion in 11 patients was located in the border region of the temporal, parietal, and occipital cortex (Pats. 01, 02, 03, 08, 09, 11, 14, $15,16,18$, and 19) referred to in the following as the superior temporal, ST, group). These patients form our region-of-interest group. In addition, five patients showed damaged in the lateral parietal cortex above the angular gyrus (referred as the LP group, Pats. 04, 06, 10, 17, 20), and seven had a lesion located in the inferior temporal cortex extending into the temporal pole (referred to as the IT group). Three patients from this latter group participated in an earlier investigation on the discrimination and retention of the spatial frequency of stationary gratings (Greenlee et al., 1993). Twelve patients were taking antiepileptic medication at the time of study (Table 1). The 23 control subjects were matched on age, sex, and handedness. The mean age of the patients was 39.7 years, $\mathrm{SD}=13.4$ years (range, $18-64$ years), and that of the control group was 41 years, $\mathrm{SD}=14.1$ years (range, 23-67 years). There was no significant difference between the mean ages of the three patient groups $[F(2,22)=0.84, p>0.4]$.

Analysis of lesion area and memory test. The location and extent of the lesioned area were determined using pre- and postoperative (made 8 weeks or more after surgery) computed tomograms and magnetic resonance images, as well as the protocol from surgery. An outline of the lesioned area was transferred onto standardized templates derived from a computed tomographic atlas (Seeger, 1978; Nadjmi et al., 1991). The templates were then stacked appropriately to yield a pseudo 3-D representation. These reconstructions are shown for each patient in Figure 1 , the darkly shaded areas representing the extent and location of the lesion.

To assess general memory abilities, a neuropsychological block-tapping test was conducted, the so-called Corsi Test (Milner, 1971; Smirni et al., 1983). The test consists of nine black cubes $(2.5 \times 2.5 \times 2.5$ $\mathrm{cm})$ fixed onto a gray plastic board $(28 \times 23 \mathrm{~cm})$. The nine blocks were arranged according to the original design. After instructing the patient or subject in how to perform the test, the experimenter began by tapping four of the nine blocks. In order for the trial to be scored as correct, the patient or subject had to tap the same blocks in the same order. Each trial was conducted three times, each trial using a different sequence. The difficulty of the task was increased by increasing the number of blocks tapped. The resulting score was based on the number of blocks (excluding the first block) that were correctly tapped on two of the three trials. The mean score was $5.57 \pm 0.66$ for the patients and $5.62 \pm 0.74$ for the controls (not significant). The subjects ability to recall a series of single digits was assessed using the Digit Span Test (Wechsler, 1987). The mean score on this test was $8.6 \pm 1.67$ for the patients, and $9.4 \pm 2.2$ for the controls (not significant). When necessary, visual fields were determined by automatic visual perimetry in the University Eye Clinic in Freiburg.

Stimuli. The experimental design is illustrated in Figure 2. Sinewave luminance gratings of vertical orientation were produced by a specially designed graphics board (VSG2, Cambridge Research Systems) and a 386-computer, which provided the control signals to a high-resolution display (DM2, Joyce Electronics). Two digital-to-analog converters yielded independent voltage outputs wilh 12-bit resolution. The Joyce display has a white (P4) phosphor, a frame rate of $100 \mathrm{~Hz}$, each frame consisting of 1000 raster lines, with an average mean luminance of 150 $\mathrm{cd} / \mathrm{m}^{2}$. The control voltage-luminance characteristic of the display is linear within the range used, which was achieved by appropriate lookup tables and calibrated with a spot photometer. The contrast of the grating stimuli was modulated in space by a raised cosine function (width $2^{\circ}$ ). The temporal characteristics of the grating contrast was controlled on each presentation by a Gaussian envelope, which had a time constant of $110 \mathrm{msec}$, such that $95 \%$ of the energy was presented within $440 \mathrm{msec}$. The spatial frequency of the grating stimuli was constant at $1.6 \mathrm{c} / \mathrm{deg}$. The center of the spatial window was offset by $4^{\circ}$ on either side of the centrally located fixation point. The stimuli extended vertically along the entire height of the display $\left(10^{\circ}\right)$. Contrast was defined by the Michelson equation,

$$
C=\left(L_{\max }-L_{\min }\right) /\left(L_{\max }+L_{\min }\right),
$$

where $L_{\max }$ is the maximum luminance level and $L_{\min }$ the minimum level. 
Table 1. Clinical data on the 23 patients who participated in the study (GM, grand mal; VF, visual field)

\begin{tabular}{|c|c|c|c|c|c|c|c|c|c|}
\hline Patient & $\begin{array}{l}\text { Tesioned } \\
\text { side }\end{array}$ & $\begin{array}{l}\text { I.esion } \\
\text { location }\end{array}$ & $\begin{array}{l}\text { Age } \\
\text { (years) }\end{array}$ & Sex & Diagnosis & $\begin{array}{l}\text { Date of } \\
\text { surgery }\end{array}$ & $\begin{array}{l}\text { Symptoms prior } \\
\text { to surgery }\end{array}$ & $\begin{array}{l}\text { Symptoms at time } \\
\text { of study }\end{array}$ & $\begin{array}{l}\text { Medication (possibly } \\
\text { sedative) at time } \\
\text { of study }\end{array}$ \\
\hline PAT01 & $\mathrm{L}$ & ST & 51 & $\mathbf{M}$ & Cavernoma & $11 / 90$ & GM in 1983,1987 & None & None \\
\hline PAT02 & $\mathrm{L}$ & ST & 64 & $\mathbf{M}$ & $\begin{array}{l}\text { Meningioma } \\
\quad(\text { WHO I })\end{array}$ & $6 / 83$ & $\begin{array}{l}\text { Mild aphasia, } \\
\text { dysgraphia }\end{array}$ & Mild dysnomia & Zentropil (phenytoin) \\
\hline PAT03 & $\mathrm{L}$ & ST & 38 & M & $\mathrm{a}-\mathrm{v}$ Angioma & $5 / 91$ & $\begin{array}{l}\text { Lower right VF } \\
\text { defect }\end{array}$ & Lower right VF defect & None \\
\hline PAT04 & $\mathrm{L}$ & LP & 23 & $\mathbf{M}$ & $\begin{array}{l}\text { Astrocyloina } \\
\text { (WHO II) }\end{array}$ & $5 / 91$ & GM in 1991 & $\begin{array}{l}\text { Mild disorientation during } \\
\text { head movements }\end{array}$ & None \\
\hline PAT05 & $\mathbf{L}$ & IT & 31 & F & $\begin{array}{l}\text { Astrocytoma } \\
\qquad(\text { WHO I) }\end{array}$ & $1 / 92$ & Partial seizures & None & $\begin{array}{l}\text { Timonil } \\
\text { (carbamazapine) }\end{array}$ \\
\hline PAT06 & $\mathrm{L}$ & LP & 35 & F & Cavernous angioma & $10 / 89$ & GM in 1989 & None & Timonil \\
\hline PAT07 & $\mathrm{L}$ & IT & 34 & $\mathbf{M}$ & a-v Angioma & $7 / 89$ & $\begin{array}{l}\text { Complex partial } \\
\text { seizures }\end{array}$ & None & Timonil \\
\hline РАT08 & $\mathrm{L}$ & ST & 62 & $\mathbf{M}$ & $a-v$ Angioma & $2 / 92$ & GM since 1982 & Mild dysnomia & Zentropil \\
\hline PAT09 & $\mathrm{L}$ & ST & 57 & $\mathbf{M}$ & $\begin{array}{l}\text { Astrocytoma } \\
\text { (WHO II) }\end{array}$ & $9 / 88$ & GM in 1988 & None & $\begin{array}{l}\text { Tegretal } \\
\text { (carbamazapine) }\end{array}$ \\
\hline PAT10 & $\mathbf{L}$ & LP & 30 & M & $a-v$ Angioma & $3 / 91$ & Dystaxia & Dystaxia & None \\
\hline PAT11 & $\mathrm{L}$ & ST & 40 & M & Cavernoma & $5 / 92$ & GM in 1992 & Mild dysphasia & Tegretal \\
\hline PAT12 & $\mathrm{L}$ & IT & 29 & $\mathrm{~F}$ & Cavernous angioma & $10 / 85$ & GM in 1985 & Recurrent GM & $\begin{array}{l}\text { Mylepsinum } \\
\text { (primidon) }\end{array}$ \\
\hline PAT13 & $\mathrm{L}$ & IT & 41 & $\mathbf{F}$ & Cavernoma & $2 / 91$ & GM in 1986 & Recurrent GM & Tegretal, Zentropil \\
\hline PAT14 & $\mathrm{R}$ & ST & 32 & F & $\begin{array}{l}\text { Oligodendroglioma } \\
\text { (WHO II) }\end{array}$ & $3 / 86$ & $3 \mathrm{GM}$ in 1985 & None & None \\
\hline PAT15 & $\mathrm{R}$ & ST & 20 & $\mathbf{M}$ & $\begin{array}{l}\text { Astrocytoma } \\
\text { (WHO II) }\end{array}$ & $2 / 91$ & GM in 1991 & None & None \\
\hline PAT16 & $\mathrm{R}$ & ST & 18 & $\mathbf{F}$ & $\begin{array}{l}\text { Astrocytoma } \\
\text { (WHO II) }\end{array}$ & $1 / 90$ & $\begin{array}{l}\text { Complex partial } \\
\text { seizures since } \\
1984\end{array}$ & Lower left VF defect & None \\
\hline PAT17 & $\mathrm{R}$ & LP & 61 & $\mathrm{~F}$ & v. Angioma & $12 / 90$ & Partial seizures & $\begin{array}{l}\text { Difficulties with reading } \\
\text { and writing }\end{array}$ & Mylepsinum \\
\hline PAT18 & $\mathbf{R}$ & ST & 51 & $\mathrm{~F}$ & Stroke (1984) & - & None & None & None \\
\hline PAT19 & $\mathbf{R}$ & ST & 54 & F & Cavernous angioma & $1 / 87$ & $4 \mathrm{GM}$ in $1984-86$ & None & Tegretal \\
\hline PAT20 & $\mathbf{R}$ & LP & 35 & $\mathbf{F}$ & Cavernous angioma & $2 / 87$ & GM in 1985 & None & Tegretal \\
\hline PAT21 & $\mathbf{R}$ & IT & 30 & $\mathrm{~F}$ & Cavernous angioma & $2 / 90$ & $2 \mathrm{GM}$ in 1990 & None & None \\
\hline PAT22 & $\mathrm{R}$ & IT & 39 & $\mathrm{~F}$ & $a-v$ Angioma & $11 / 86$ & $\begin{array}{l}\text { Recurrent GM } \\
\text { since } 1980\end{array}$ & None & Zentropil \\
\hline PAT23 & $\mathrm{K}$ & II' & 40 & $\mathrm{~F}$ & $\begin{array}{l}\text { Astrocytoma } \\
\text { (WHO II) }\end{array}$ & $5 / 90$ & GM in 1990 & None & Tegretal \\
\hline
\end{tabular}

To eliminate fixed local cues, each stimulus was presented with an initial spatial phase that was random with respect to the center of the spatial window. The gratings drifted either to the left or to the right at a rate varying from 1 to $10 \mathrm{~Hz}$ (velocities between $0.625^{\circ}$ and $6.25 \% \mathrm{sec}$ ).

Procedure. Two measurements were conducted. In both experiments, the observers binocularly viewed the display from a distance of 0.84 $\mathrm{m}$. Constant distance and head orientation was maintained by having the observer place his or her head on a chin-forehead rest. The observers were instructed to fixate a centrally located black Letraset circle that was attached to the glass surface of the display. In the first measurement, contrast detection thresholds were determined in a two-alternative forced choice procedure. Each trial was announced by a computer-generated auditory tone. Within each trial, a stimulus was presented randomly to the left or right of the fixation point. The observer's task was to signal whether the stimulus was presented left or right of fixation. Detection thresholds were determined by a staircase procedure, in which 1 of 40 contrast levels was presented on every trial. The range of contrast values was selected such that the midpoint would be approximately at threshold detection level. An estimate of threshold was made using a maximum-likelihood procedure, the Best-PEST algorithm, parametric estimation by sequential testing (Lieberman and Pentland,
1982). Contrast detection thresholds were measured for three drift rates $(1,2$, and $4 \mathrm{~Hz})$ for the left and right visual fields separately. Both gratings drifted either to the left or to the right and this direction was randomized over trials.

In the second experiment, speed discrimination thresholds were determined for these grating stimuli, with a contrast that was adjusted to be five times the value of detection threshold, averaged over both hemifields, for the reference drift rate. This suprathreshold contrast value was determined for each observer separately. Although perceived contrast can covary with stimulus speed, stimulus contrast was held constant throughout the measurement. This was done to avoid confoundations between variations in stimulus speed and contrast, since it is known that the perceived speed of eccentrically presented stimuli also covaries with contrast (Thompson, 1982; Stone and Thompson, 1992). On each trial, two gratings were presented, one having the reference velocity $\mathrm{V}_{\mathrm{ref}}$ of, on average, $1.25 \% \mathrm{sec}$ (drift rate, $2 \mathrm{~Hz}$ ), and the other having a velocity corresponding to $V_{\text {test }}=V_{\text {ref }}-\Delta V$ or $V_{\text {ref }}+\Delta V$. A random value was added to or subtracted from $V_{\text {ref }}$, which could vary up to $20 \%$ of $V_{\text {ref }}$. This random jitter was included to assure us that the subject could not make a decision based on the presentation of the first grating alone. The order in which the reference and test gratings were presented was randomly determined by the computer. The presentation 


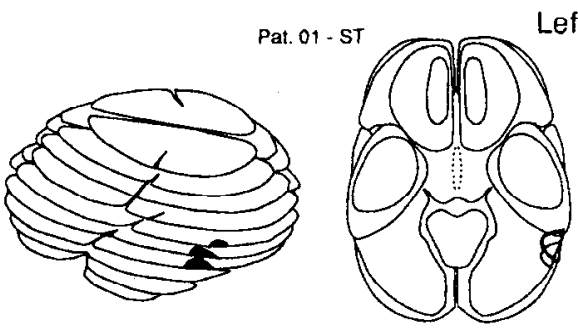

Left-Hemisphere Patients
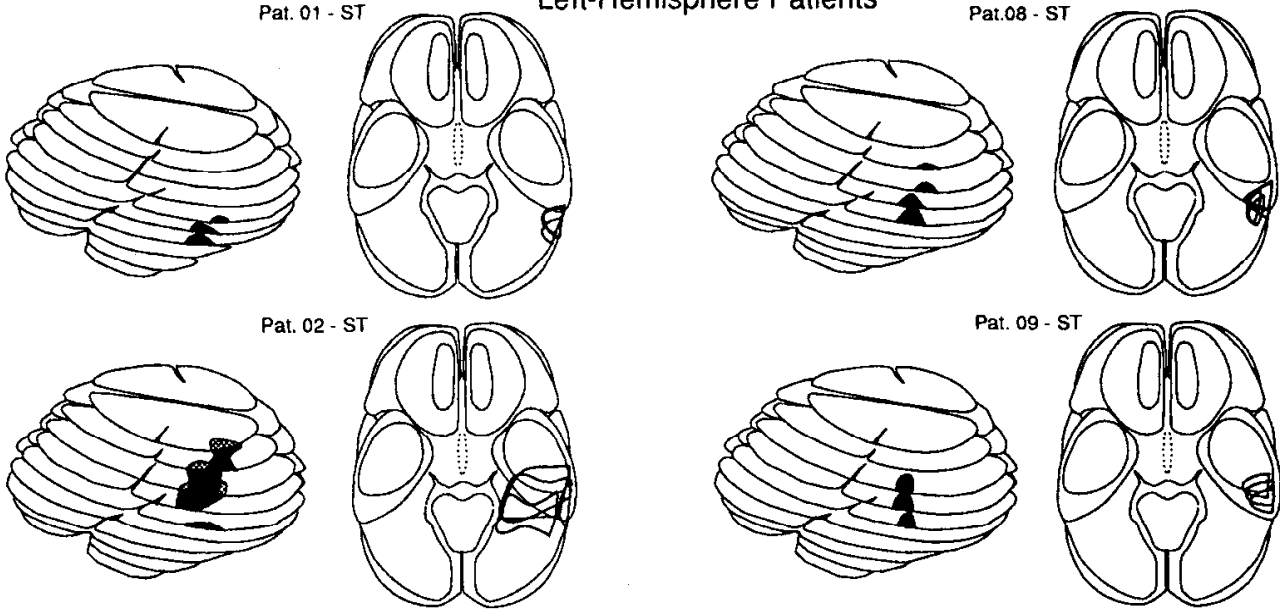

Pat. 09 - ST
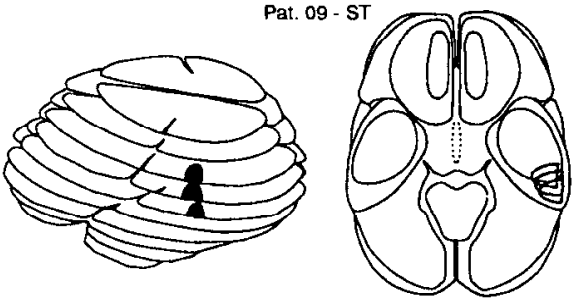

Pat.03 - ST
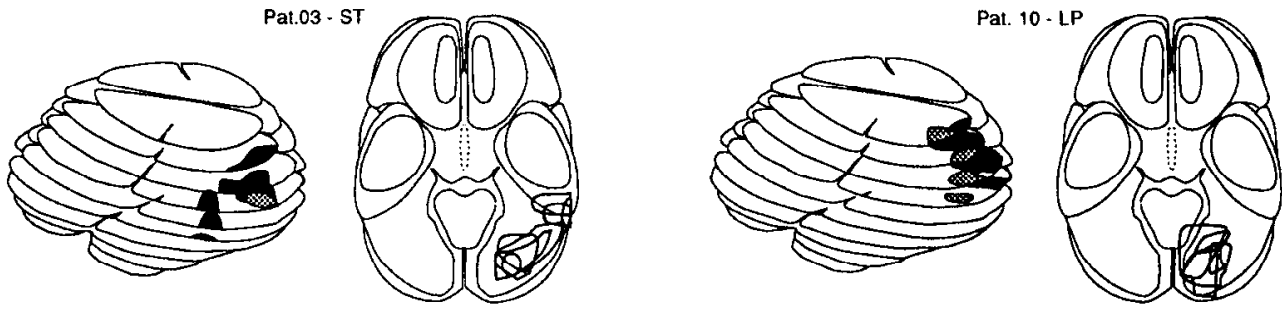

Pa1. 04 - LP
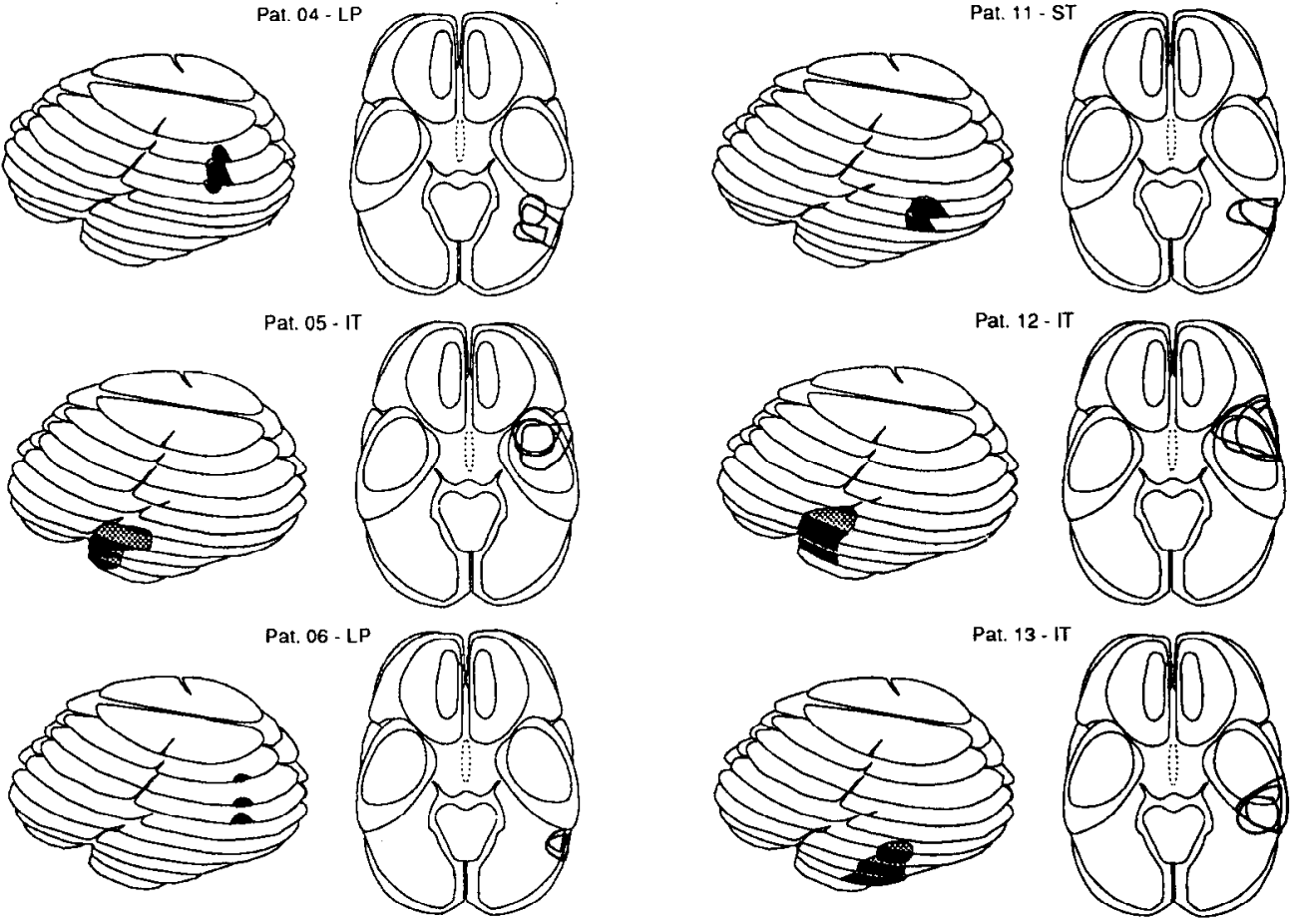

Pat. 13 - I

Figure 1. Schematic representation of the computed tomograms of 13 patients with a lesion in the left cerebral hemisphere (left panel) and 10 patients with a lesion in the right cerebral hemisphere (right panel). The group classification of the patients is denoted by the abbreviations $S T$ (superior temporal), $I T$ (inferotemporal), and $L P$ (lateral parietal).
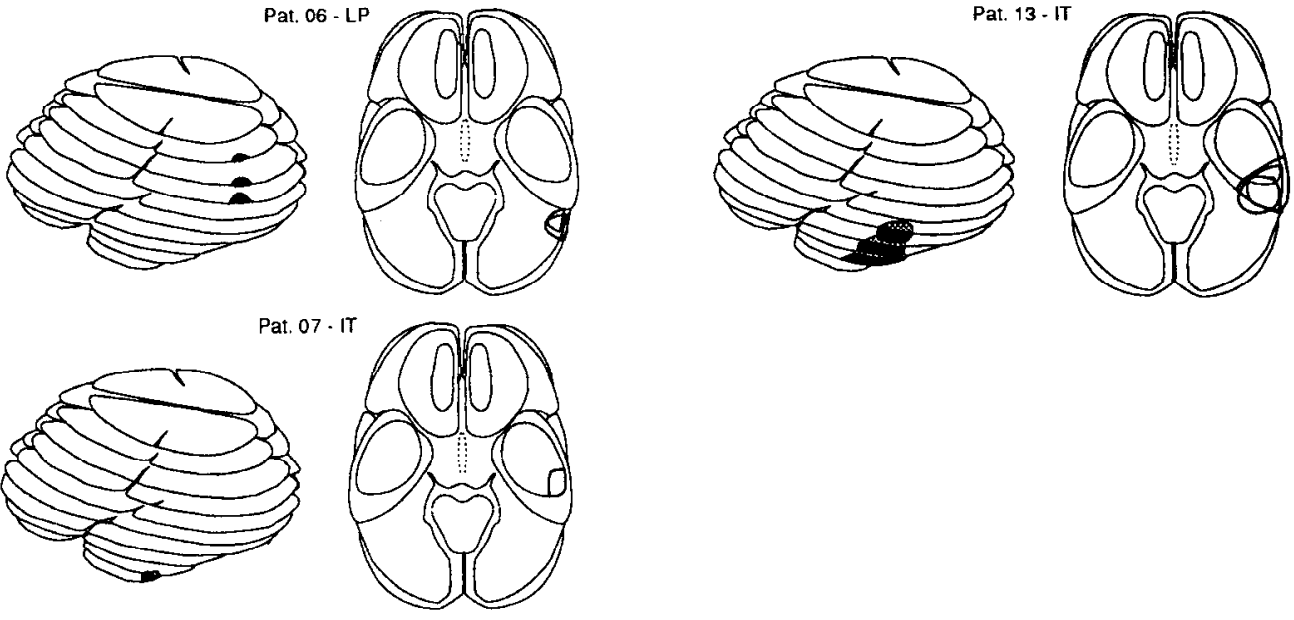


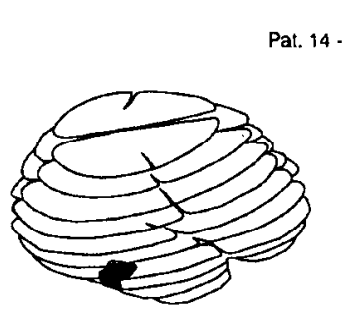

Pat. 15 - ST
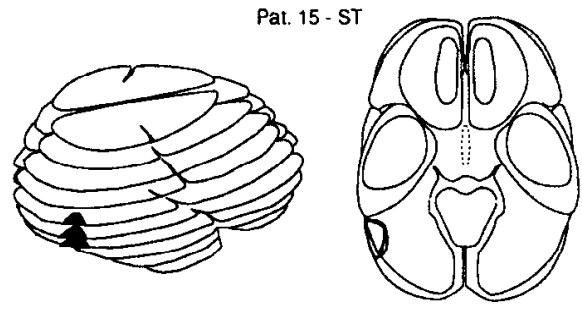

Pat. $10 \cdot \mathrm{ST}$
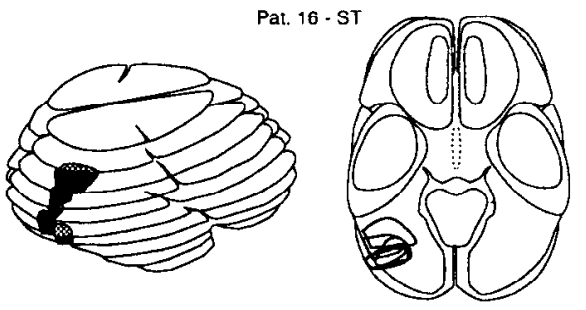

Pat. $17 \cdot$ LP
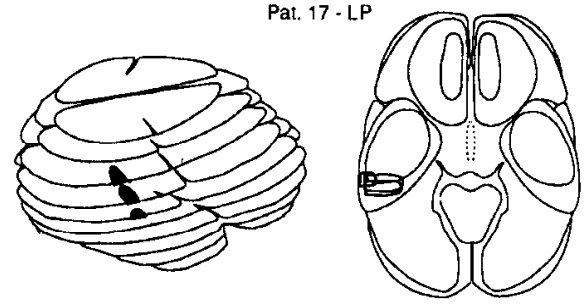

Pat. 18 - ST
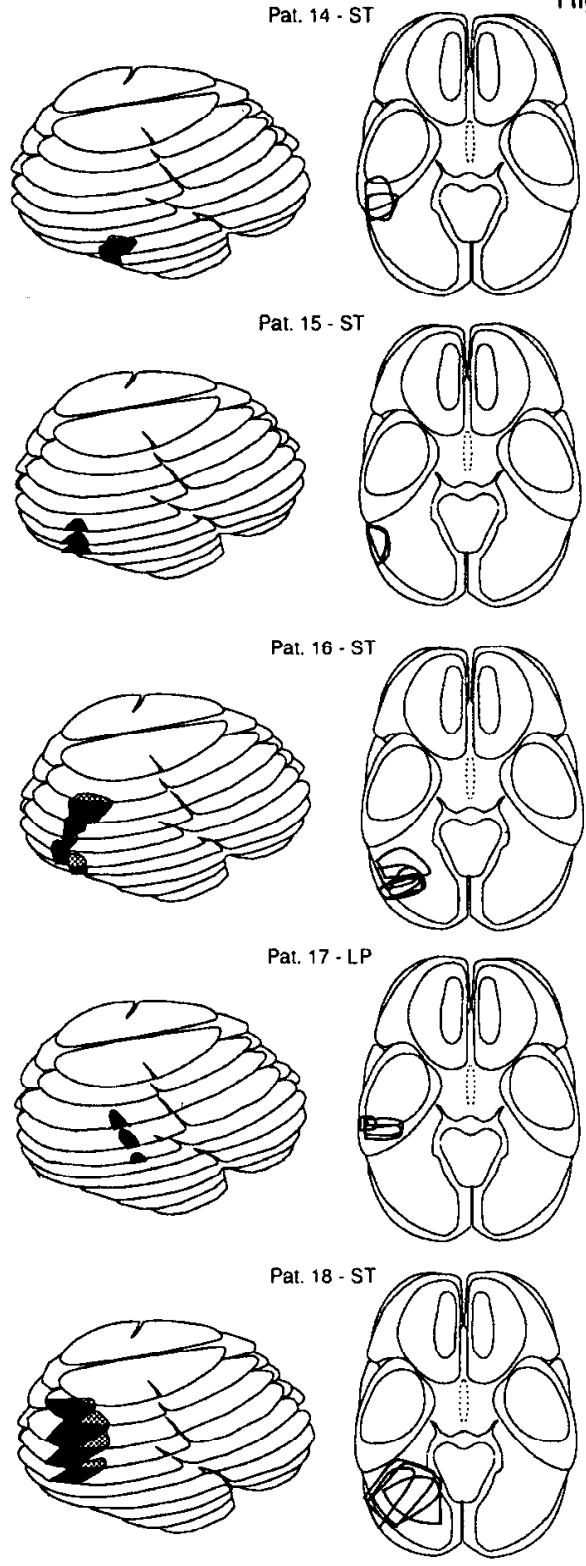

Right-Hemisphere Patients
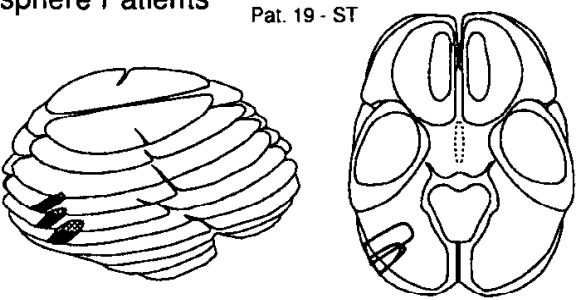

Pat. 20 - LP
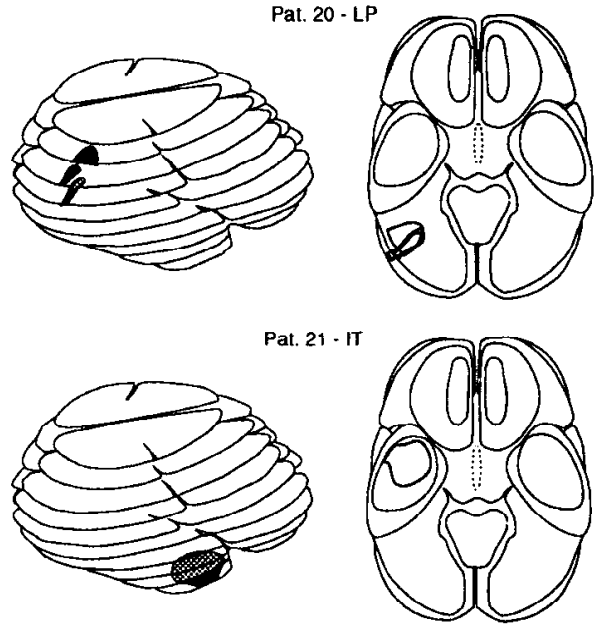

Pat. $22 \cdot \pi$
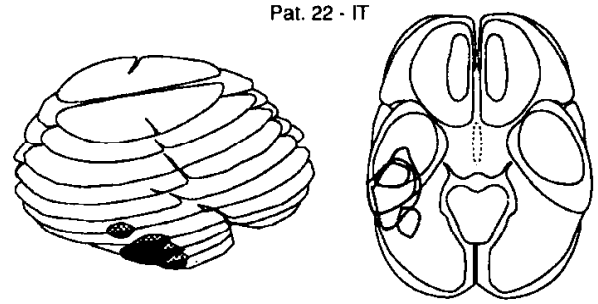

Pat. $23 \cdot$ IT
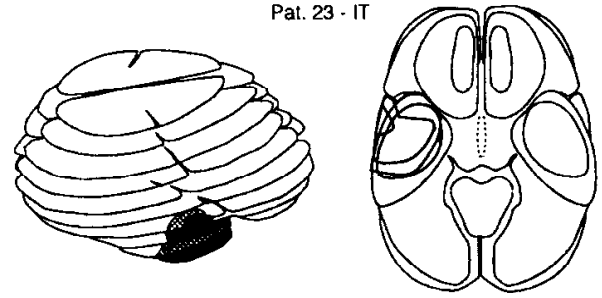

Figure 1. Continued. of the test and reference grating was separated in time by an interstimulus interval (ISI) which was either $0,1,3$, or $10 \mathrm{sec}$ in duration. For the simultaneous discrimination condition, in which ISI $=0 \mathrm{sec}$, the gratings were presented left and right of fixation with no delay. In the sequential discrimination conditions (ISI $>0$ ), the second pattern was randomly presented in half of the trials in the same hemifield, the other half in the opposite hemifield. The results are analyzed with respect to the location of the reference (left visual field, LVF; right visual field, RVF) and whether the test was in the same or opposite visual field (see below). The observer's task was to signal which grating had the higher speed in a two-alternative forced-choice task. Speed discrimination thresholds were estimated using a staircase technique that controlled the value of $\Delta V / V$, which could range from 0.05 to 2.0 in increments of 0.05 . In cases where $\Delta V / V$ exceeded $1.0, \Delta V$ was always added to $V_{\text {ref }}$, so as not to allow $V_{\text {test }}$ to take on negative values. The same maximum likelihood algorithm described above was used to provide an estimate of the discrimination threshold, which was defined as the $75 \%$ correct performance level. The maximum likelihood estimation was determined for each of 40 trials; the estimate given after the 40th trial was defined as the threshold value.

In a subset of five patients and five control subjects, spatial frequency discrimination thresholds for stationary gratings were also determined. The spatial characteristics and eccentricity of the grating patches were identical to those described above, with the exception that the reference spatial frequency was $5 \mathrm{c} / \mathrm{deg}$. The contrast of the gtatings was also varied as a Gaussian function of time with the same $110 \mathrm{msec}$ time constant. The gratings were stationary during their presentation and contrast was adjusted to be five times higher than the contrast required to detect the gratings. The subjects responded, in a forced-choice paradigm, which grating had the higher spatial frequency. The interstimulus interval was zero (simultaneous presentation) or 1,3 , or $10 \mathrm{sec}$ (sequential presentation). Added to or subtracted from this reference spatial frequency was a random jitter that could vary up to $10 \%$ of the reference value.

\section{Results}

\section{Contrast sensitivity to drifting gratings}

The results of the contrast detection threshold measurements are shown in Figure 3. The logarithm of the inverse of detection threshold, contrast sensitivity, is shown as a function of the drift rate $(\mathrm{Hz})$. Panel a shows the results for 11 patients with damage in the superior temporal cortex (ST, our region of interest), panel b presents the results for 7 patients with damage in the inferotemporal cortex (IT), panel $\mathrm{c}$ shows the results for 5 patients 
REFERENCE STIMULUS

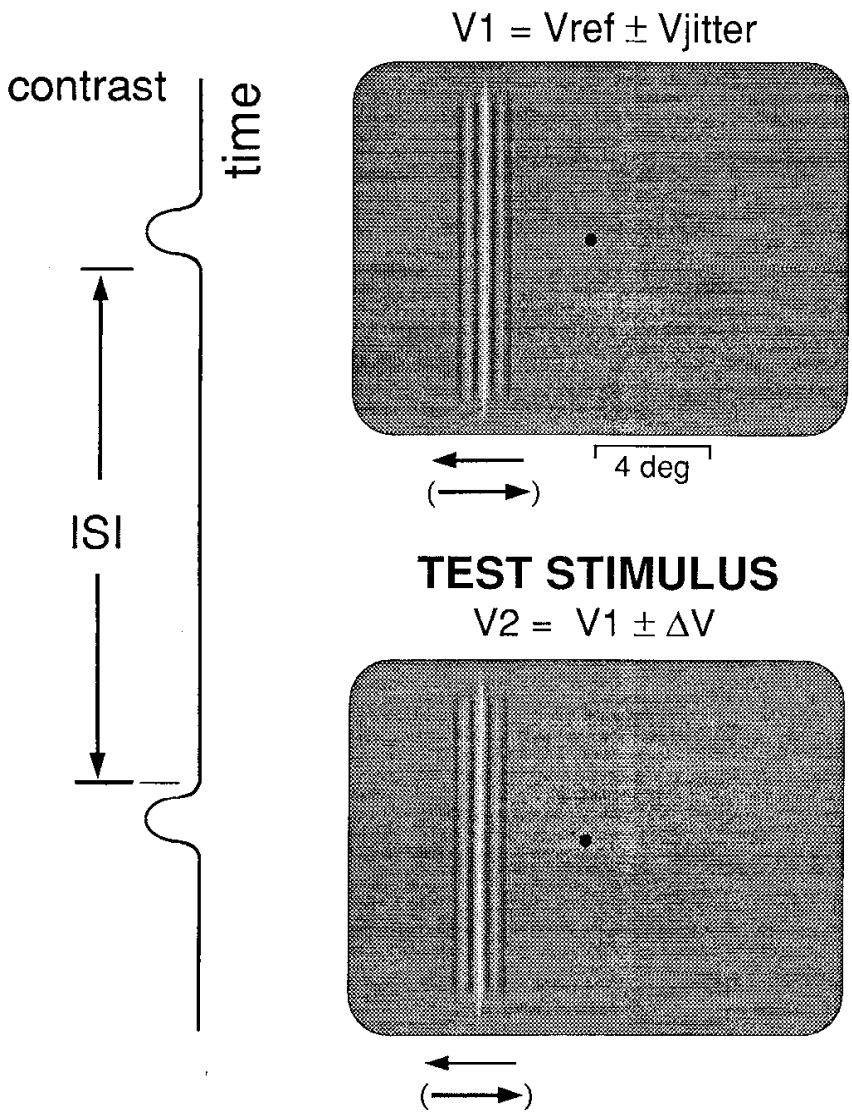

Figure 2. Schematic illustration of the experimental paradigm used to determine velocity discrimination thresholds.

with damage in the lateral parietal cortex (LP), and panel d gives the results of the 23 control subjects. In the patient groups, the circles show the results for observers with left hemisphere (LH) damage and squares present the results for observers with right hemisphere (RH) damage. Filled symbols give the results for stimuli presented to the observers' ipsilesional visual field and open symbols show the results for contralesional stimulus presentation. The symbols show the mean values and the error bars give one standard crror (SE) of the mean. Filled and open circles represent the values for the controls for LVF and RVF presentation (panel d).

A four-way analysis of variance was performed on the logarithm of the contrast sensitivity values, which tested the effects of the between-subjects factor group (i.e., patients vs. controls), and the within-subjects factors visual field (LVF, RVF), drift direction (leftwards, rightwards), and drift rate (1, 2, and $4 \mathrm{~Hz}$ ). Log contrast sensitivity significantly increased with drift rate $[F(2,90)=24.8, p<0.0001]$, which is in agreement with earlier results (Robson, 1966). The main effects of visual field $[F(1,44)$ $=0.94, p=0.34]$, drift direction $[F(1,44)=0.65, p=0.42]$ and experimental group $[F(1,44)=1.65, p=0.2]$ were not significant. Overall the patients had a mean contrast detection threshold of 0.0057 (contrast sensitivity $=175.4$ ) and the controls showed a mean threshold of 0.0053 (contrast sensitivity $=$ 188.7). This absence of a significant group difference indicates that the patients were unimpaired with respect to their ability to detect the eccentrically presented grating stimuli. Within the patient group, the side on which the cerebral hemisphere was dam- aged (i.e., $\mathrm{LH}$ vs $\mathrm{RH}$ ) also had no significant effect on contrast sensitivity $[F(1,21)=0.45, p=0.51]$, nor did this factor interact significantly with the effects of the visual field in which the stimulus was presented $[F(1,21)=0.81, p=0.38]$ and/or with drift direction $[F(1,21)=0.33, p=0.57]$. Comparing log sensitivity over the three patient groups, there was a marginally significant tendency for the ST patients to exhibit higher detection thresholds $[F(2,20)=3.703, p=0.043]$. The mean $\log$ sensitivity of the ST patients was $0.1 \mathrm{log}$ unit lower than that of the IT and LP patients.

\section{Velocity discrimination of simultaneously presented stimuli}

The results of the velocity discrimination experiments for simultaneously presented stimuli are shown in Figure 4 . The Weber fraction for velocity discrimination $\Delta V / V$ is shown for the three patient groups, separately for patients with damage to the left and right hemispheres. The hatched horizontal bar gives the mean discrimination threshold $\pm 1 \mathrm{SE}$ for the 23 control subjects. Since both left and right visual fields were stimulated simultancously, and subjects had to judge which stimulus was moving faster, the effect of visual field cannot be analyzed here. There is a tendency for the ST patients to exhibit higher discrimination thresholds for simultaneously presented stimuli. The overall difference between the patients and controls was, however, not significant $[F(1,44)=2.35, p=0.12]$. The mean Weber fraction for simultaneous discrimination was $0.597 \pm 0.067$ for the patients and $0.476 \pm 0.042$ for the controls. Compared to the IT and LP patients, the ST patients showed, on average, higher discrimination thresholds, especially those with left hemisphere damage. A separate ANOVA conducted on the patient data showed that the main effect of lesion location was only marginally significant $[F(2,20)=3.05, p=0.07]$. The same analysis revealed that the main effect of damaged hemisphere $[F(1,21)=0.74, p=0.4]$ and the interaction lesion location $\times$ hemisphere $[F(5,17)=1.6, p=0.21]$ were also not significant.

\section{Velocity discrimination of stimuli presented with a delay}

The Weber fraction for velocity discrimination $\Delta V / V$ is shown in Figure 5 as a function of the interstimulus interval (sec). Panel a presents the findings for the ST patients, panel $b$ for the IT patients, panel $c$ for the LP patients, and panel $d$ shows the results for the control subjects. Circles present the findings when the reference stimulus was presented in the visual field ipsilateral to the patient's damaged hemisphere (LVF for the controls), and squares show the results for reference stimuli presented in the visual field contralateral to the damaged hemisphere (RVF for the controls). Filled symbols present the findings for the condition in which the test stimulus was presented in the same visual field as the reference, and open symbols show the results for test stimuli presented in the opposite visual field. Velocity discrimination thresholds are markedly elevated in the ST patients and this elevation in discrimination thresholds becomes more pronounced with increasing delay (panel a). Velocity discrimination thresholds are slightly more elevated for stimuli presented in the visual field contralateral to the damaged hemisphere in the ST patients. The IT patients also exhibit elevated discrimination thresholds, but these thresholds do not increase with increasing delay (panel b). Although there is more scatter in their data, the five LP paticnts do not, gencrally, exhibit elevated thresholds, with the possible exception of the $3 \mathrm{sec}$ ISI condition and contralesional presentation of both reference and test stimuli. In support of earlier findings (Magnussen and Greenlee, 
a)

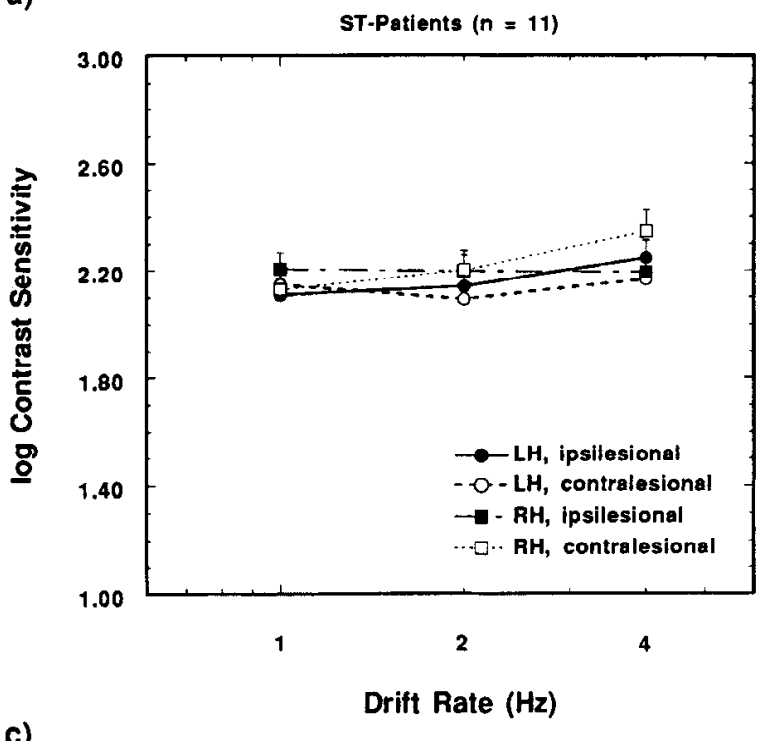

c)

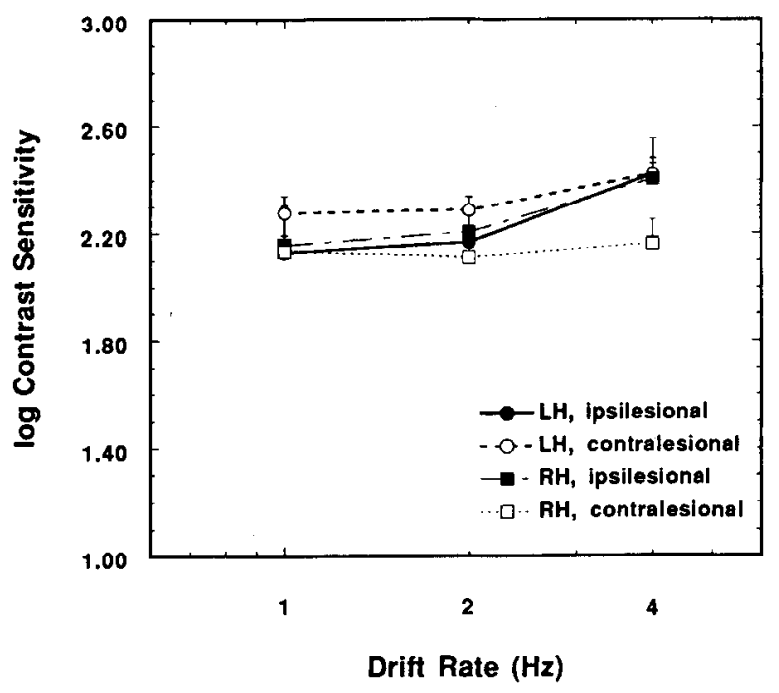

b)
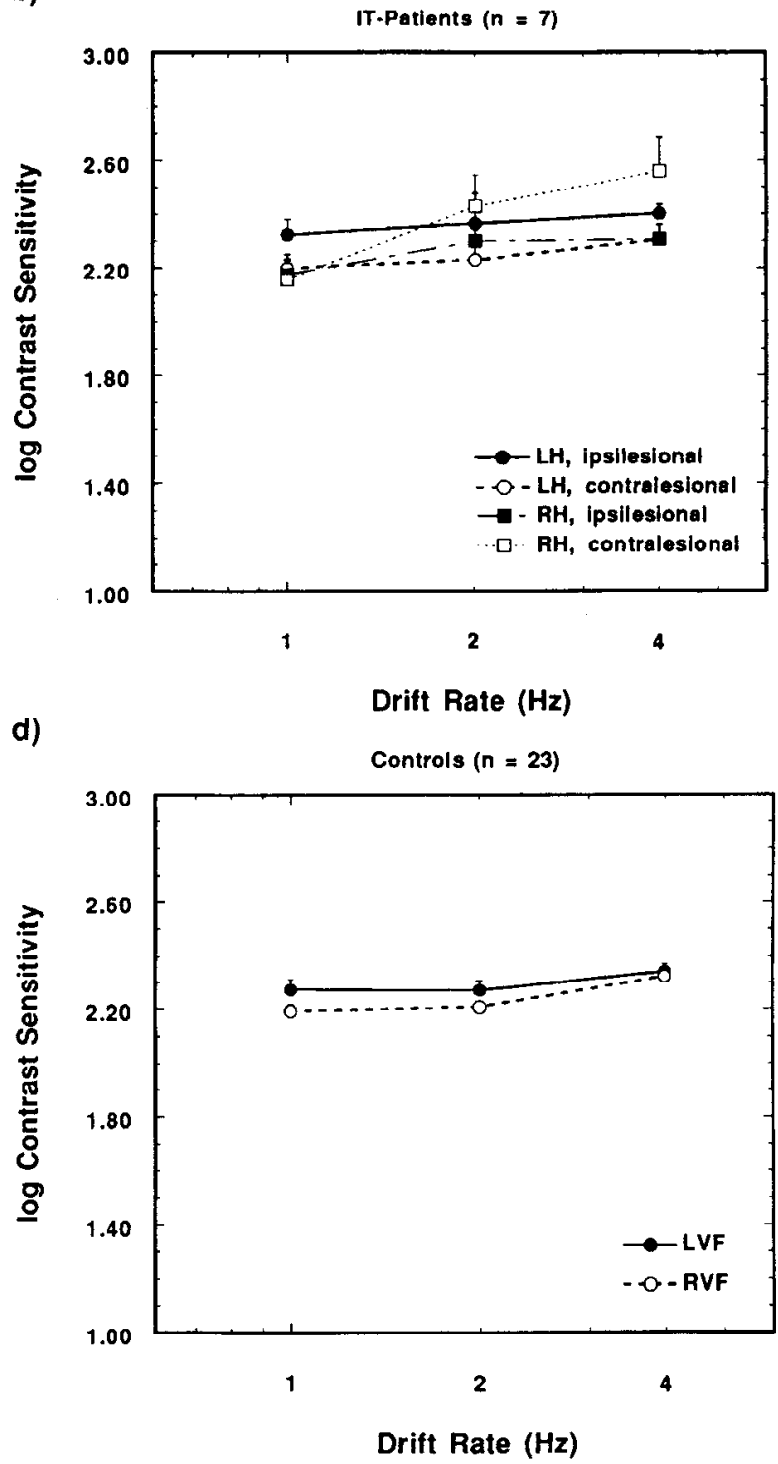

Figure 3. Mean $\log$ contrast sensitivity for sinusoidal grating patches presented in the ipsilesional ( $f$ illed symbols) and contralesional visual fields (open symbols) for patients with left hemisphere (circles) and right hemisphere lesions (squares) as a function of the drift rate of the gratings. The contrast of the gratings varied as a Gaussian function of time, with a time constant of $110 \mathrm{msec}$. The center of the spatial window was $4^{\circ}$ to the right or left of a central fixation point. Panels $a-d$ present the findings for the three patient groups (ST, IT, LP) and the control subjects, respectively.

1992), the control subjects did not show a noticeable effect of ISI, with the exception that thresholds for simultaneous presentation were slightly lower than for sequential presentation (compare Figs. 4, 5).

A four-way analysis of variance was performed on the velocity discrimination thresholds for stimuli presented with a delay, which tested for the statistical significancc of the between-subjects factor group (patients vs. controls), and the within-subjects factors visual field of reference stimulus (ipsilesional-contralesional for the patients; LVF-RVF for the controls), relative position of the test stimulus (same, opposite VF), and the ISI. This analysis revealed a highly significant effect of group on the velocity discrimination thresholds $[F(1,44)=9.5, p<0.004]$, indicating that the 23 patients with unilateral cortical damage, viewed as a single group, had significantly higher thresholds than the age-matched control subjects. In a separate ANOVA, the controls showed no effect with respect to the position of the reference stimulus $[F(1,22)=0.9, p=0.35]$ or the relative position of the test $[F(1,22)=2.6, p=0.12]$. The effect of ISI was not significant in the control group $[F(2,44)=1.9, p=$ 0.16]. Separate ANOVAs performed on the patients' data revealed that the effect of lesion location on the delayed discrimination thresholds was highly significant $[F(2,20)=5.43, p=$ 0.01]. The ST patients exhibited a mean Weber fraction in the delayed discrimination task of $1.3 \pm 0.07$, compared to $0.75 \pm$ 0.04 and $0.6 \pm 0.05$ in the IT and LP patient groups. Although the overall effect of ISI in the patients was not significant $[F(2,40)=1.0, p=0.37]$, there was a significant interaction between the main effects of lesion location and ISI $[F(4,40)=$ $2.8, p=0.04]$ among the three patient groups. This latter statistical interaction substantiates the impression given in Figure 5 that the ISI had a much larger effect on velocity discrimination thresholds in the ST patients. A separate ANOVA on the data from the $11 \mathrm{ST}$ patients confirmed that the ISI had a significant 


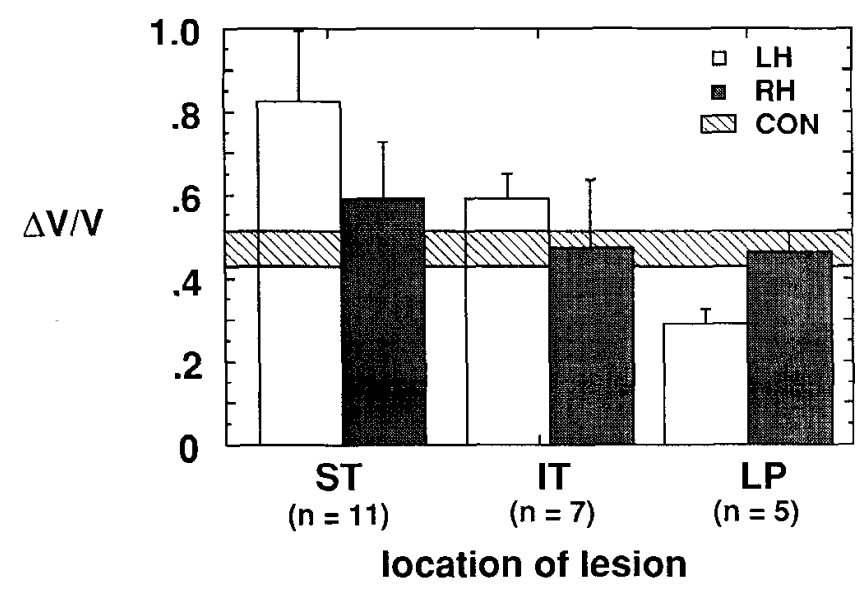

Figure 4. Mean velocity discrimination thresholds ( $\Delta V / V)$ for simultaneously presented stimuli. Open columns show the results for patients with a left hemisphere lesion and filled columns present the results for patients with a right hemisphere lesion. Error bars show 1 standard error of the mean (SE). The results are shown separately for the ST, IT, and LP patients. The horizontal striped bar gives the mean $\pm 1 \mathrm{SE}$ of the control subjects' results under the same conditions.

effect on the discrimination thresholds $[F(2,20)=5.38, p=$ $0.014]$. Post hoc comparisons (Bonferroni/Dunn) revealed, however, that this effect was mainly owing to the difference between the $3 \mathrm{sec}$ and $10 \mathrm{sec}$ ISI conditions $(p=0.006)$, whereas the difference between the 1 and $10 \mathrm{sec}$ ISI conditions was only marginally significant $(p=0.074)$.

\section{Spatial frequency discrimination of stationary gratings}

To determine the extent to which the elevations in discrimination threshold found in patients with lesions in the ST cortex are specific to the processing of stimulus velocity, we investigated a subgroup of patients using a delayed pattern discrimination task, similar to the one described in an earlier study (Greenlee et al., 1993). The subgroup comprised five ST patients from the region-of-interest group, all of whom showed significantly elevated velocity discrimination thresholds. These were the patients PAT01, PAT03, PAT09, PAT16, and PAT19 (see Table 1 and Fig. 1). The first three patients had left hemisphere damage and the last two had right-sided damage. Figure 6 (panel a) presents the Weber fraction for spatial frequency discrimination $\Delta f / f$ as a function of the interstimulus interval for ipsilesional and contralesional visual field presentation. These results are compared to those of five age-matched controls subjects for LVF and RVF presentation (panel $\mathrm{b}$ ). In the delayed discrimination task, reference and test stimuli were always presented in the same location. Although there is a tendency for spatial frequency discrimination thresholds to be slightly elevated in the patients, the results of a three-way analysis of variance indicated that the effect of group was not statistically significant $[F(1,8)=2.32$, $p=0.166]$. There was no overall tendency for thresholds to increase with increasing ISI $[F(3,24)=0.45, p=0.72]$, nor was the interaction between group and ISI significant $[F(3,24)=$ $0.15, p=0.7]$.

\section{Velocity discrimination at higher stimulus speeds}

Single-unit recordings in area MT of the macaque indicate that these neurons respond optimally to high values of stimulus velocity (Maunsell and van Essen, 1983), and that their responses saturate at low levels of stimulus contrast (Sclar et al., 1990). In the experiments reported above, we used relatively low stimulus velocities. It could be argued that differences apparent in our patients might be even more pronounced for a higher range of stimulus speeds. To explore this possibility, we retested five of our patients and compared their findings to five control subjects, by testing contrast detection thresholds and velocity discrimination thresholds at higher drift rates. The same subjects served in the spatial frequency discrimination measurements reported above. The reference drift rate of the stimuli in this experiment was $8 \mathrm{~Hz}$, corresponding to a speed of $5.0^{\circ} / \mathrm{sec}$. Velocity discriminations were made for ISIs of zero (simultaneous discrimination) and $3 \mathrm{sec}$. The results of this control experiment indicate that the differences in velocity discrimination between the patients and controls were similar to those observed in the main experiments. Velocity discrimination thresholds were significantly elevated in the patients $[F(1,8)=5.99, p=0.04]$. The mean Weber fractions for simultaneous discrimination were 0.26 for the ST patients versus 0.16 for the controls, for delayed discrimination they were 0.3 versus 0.22 for the two groups, respectively. The results of the contrast detection experiments indicated that there were no differences in the patients ability to detect drifting gratings, even at rates as high as $15 \mathrm{~Hz}$.

\section{Effect of age on contrast sensitivity and velocity discrimination}

As our paticnt and control samples varicd to a considerable cxtent in their age, we could examine the relationship between age and the psychophysically determined detection and velocity discrimination thresholds. Table 2 presents the results of a correlational analysis, in which we tested the overall correlation between age and log contrast sensitivity, as well as between age and the discrimination thresholds for velocity. This was done for all subjects together, as well as for patients and control subjects separately. The geometric mean over all conditions was calculated for cach subject and this value was correlated with the subjects' age. There is a robust correlation between the subject's age and his or her log contrast sensitivity, sensitivity declining by about $1 \mathrm{~dB}$ ( 0.05 log unit) per decade of life, in both patients and control subjects. The correlation between age and velocity discrimination thresholds is more moderate, but the tendency evident in the data suggest that the Weber fraction for velocity discrimination $(\Delta V / V)$ increases by about $0.06 /$ decade in the controls and $0.12 /$ decade in the patients.

\section{Effect of lesion location on delayed speed discriminations}

The findings illustrated in Figure 5, namely that the location of the lesion appears to play a role in the impairment of motion perception, led us to apply a further approach to investigating this aspect of the results. To this end, we performed a $\mathrm{z}$-transformation of the patients' velocity discrimination thresholds. Figure 7 shows the results of this analysis. Each patient's threshold in the discrimination task was transformed in terms of the mean and standard deviation of the control group, such that

$$
z=\left(\Delta V_{\text {pat }}-\Delta V_{\text {control-mean }}\right) / \mathrm{SD}_{\text {control. }}
$$

This $z$ value was then used to weight the effect of the cortical lesion on velocity discrimination. This was done by placing the $z$ score in the cells of a $10 \times 12$ matrix that corresponded to the location of the cerebral lesion (left panel). These matrices were developed for each of our 23 patients, and the topographic distribution of the mean values of these $z$-weighted lesioned areas are shown on a gray-level scale (right panel). This matrix is 
a)

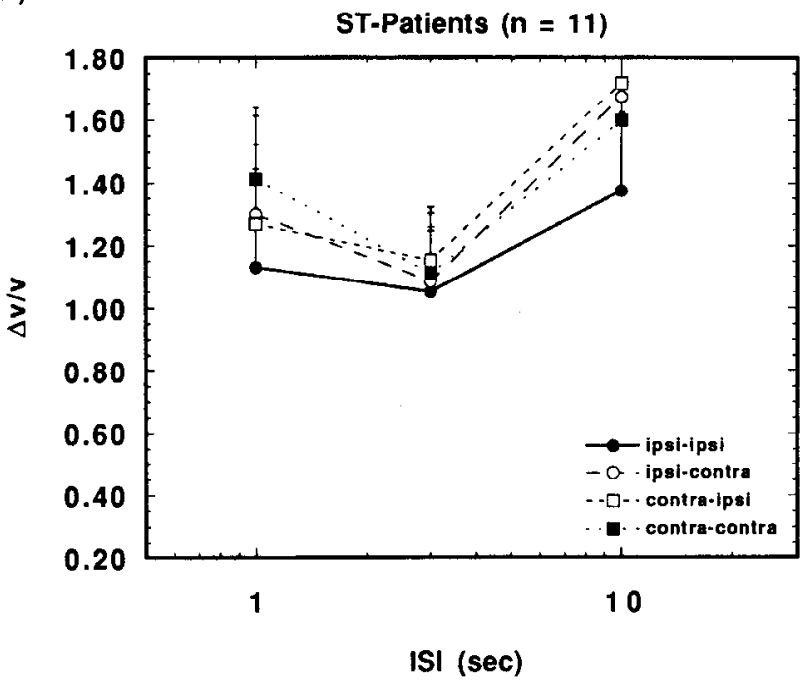

c)

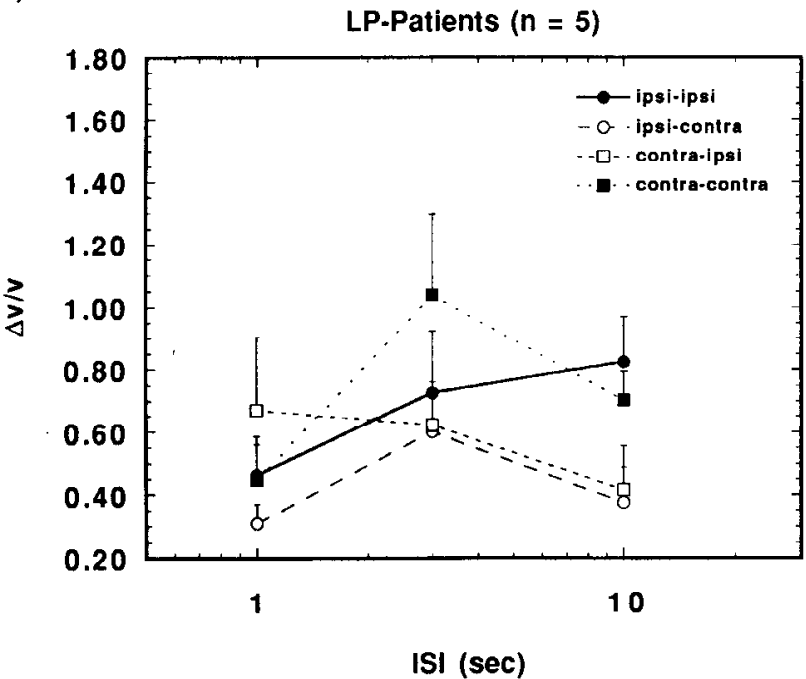

b)

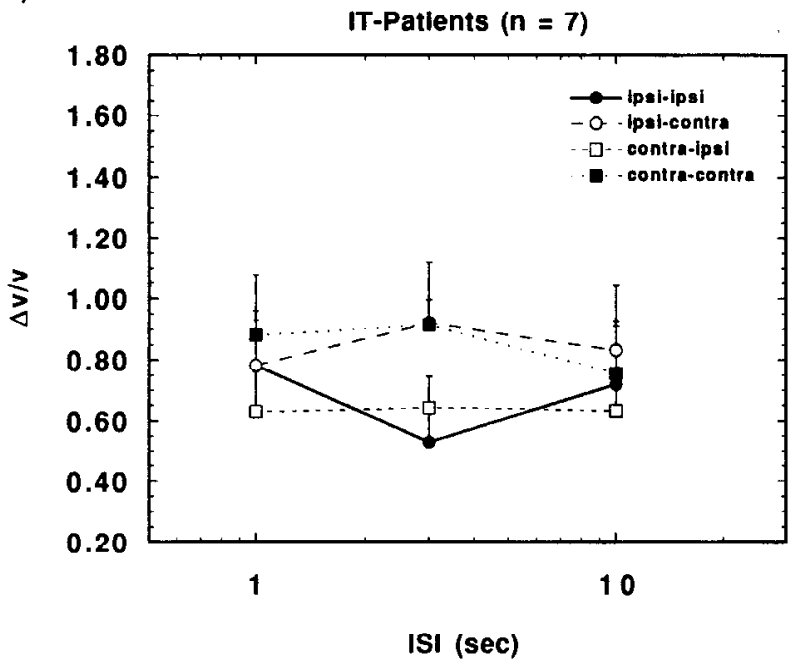

d)

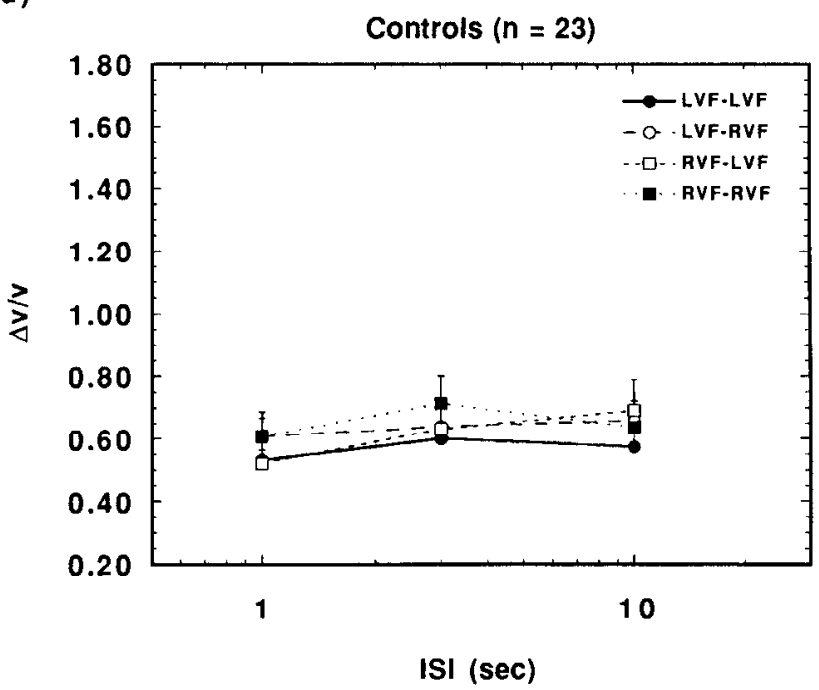

Figure 5. Mean velocity discrimination thresholds for sequentially presented stimuli shown as a function of the interstimulus interval (ISI). Filled symbols give the results when the reference and test stimuli were presented in the same visual field and open symbols present the results for stimuli presented in opposite visual fields. Circles show the findings when the reference stimulus was presented in the ipsilesional visual field and squares give the results when the reference stimulus was presented in the contralesional visual field. Panels $a-d$ present the findings for the three patient groups and for the controls, respectively.

a)

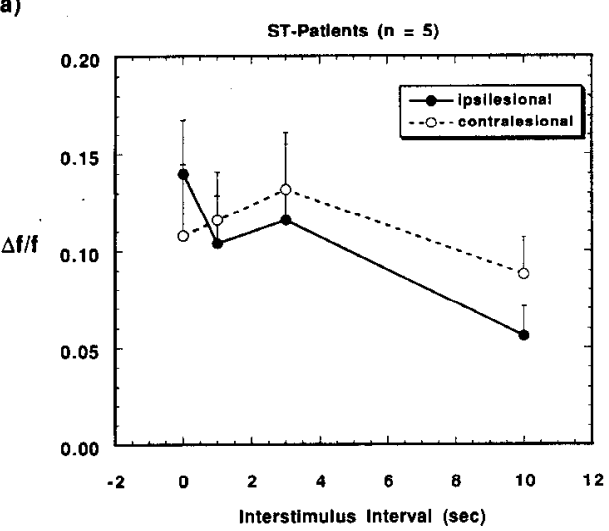

b)

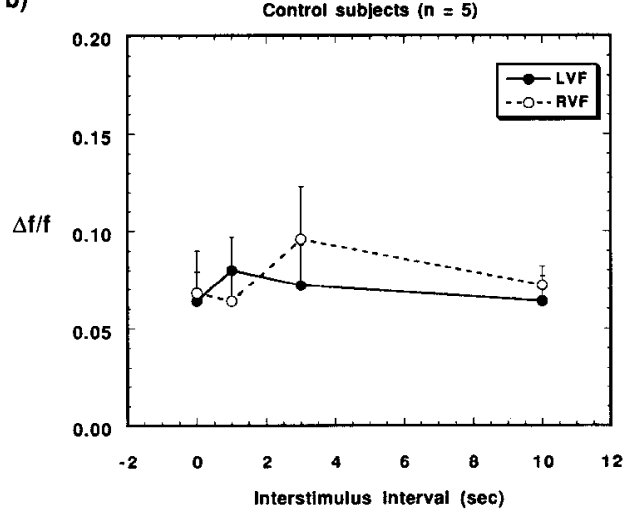

Figure 6. Mean spatial frequency discrimination thresholds $(\Delta f / f)$ for sequentially presented stationary gratings shown as a function of the interstimulus interval. Filled symbols show the results for ipsilesional visual field presentation and open symbols give the results for contralesional presentation (LVF and RVF, respectively, in the controls). Error bars show 1 SE. Panels $a$ and $b$ show the results for a subset of five ST patients and five agematched controls. 
Table 2. Results of correlational analysis performed to explore the relationship between the subjects' age and the logarithm of contrast sensitivity (upper three rows) and Weber fraction for velocity discrimination (lower three rows)

\begin{tabular}{lllllll} 
& $n$ & $r$ & $F$ & $p$ & Intercept & $\begin{array}{l}\text { slope } \\
\text { (unit/decade) }\end{array}$ \\
\hline $\operatorname{logCS}$ & & & & & & \\
$\quad$ Patients & 23 & 0.6 & 12.9 & 0.0015 & 2.46 & $-1 \mathrm{~dB}$ \\
Controls & 23 & 0.6 & 11.3 & 0.003 & 2.45 & $-1 \mathrm{~dB}$ \\
$\quad$ Total & 46 & 0.59 & 23.4 & 0.0001 & 2.47 & $-1 \mathrm{~dB}$ \\
$\Delta V / V$ & & & & & & \\
Patients & 23 & 0.35 & 3.2 & 0.09 & 0.403 & 0.12 \\
Controls & 23 & 0.41 & 4.1 & 0.056 & 0.348 & 0.06 \\
Total & 46 & 0.3 & 4.4 & 0.042 & 0.397 & 0.08
\end{tabular}

The correlation coefficient $r$ is shown for the patients and controls separately, as well as for all subjects together. The associated Fisher ratio $F$ and the significance level $p$ are also given. The last two columns present the least-squares estimated intercept value and slope (change in sensitivity or thresholds per decade of life).

based on a lateral view of the 10 computed tomogram slices stacked as shown in Figure 7, which were divided into 12 anterior-posterior segments. These $z$-weighted lesion maps were made for each of the four ISI conditions. The mean of these maps for the three delayed discrimination conditions, which include both left and right hemisphic lesions superimposed, are shown in the right panel of Figure 7. There is a clearcut peak in the distribution of the $z$ scores, which suggest that performance is most impaired when the lesion includes the posterior segment of the computer tomographic slice 5. This location corresponds to the border region between the lateral occipital and temporal cortex (the posterior-inferior part of Brodmann's area 39, bordering areas 37 and 19). In Talairach (Talairach and Tournoux, 1988) coordinates this location approximately corresponds to $\mathrm{x}=55, \mathrm{y}=-60$, and $\mathrm{z}=24$.

\section{Discussion}

The present results provide evidence that the border region between the temporal, parietal, and occipital cortex is directly involved in the visual processing required for the sequential discrimination of the velocity of drifting gratings by human subjects. The patients with damage in the region of interest had Weber fractions for the sequential discrimination of velocity that were, averaged over the ISI conditions, two times higher than the mean value of the control group $(\Delta v / v=1.26$ vs 0.613 , respectively). In contrast, no significant differences between the patients and the controls were found when the subjects merely had to detect the presence of a moving stimulus. The patients' contrast sensitivity to the eccentrically presented gratings drifting at rates between 1 and $4 \mathrm{~Hz}$ did not significantly differ from that of the control subjects (Fig. 3). This lack of difference rules out an explanation for our findings based on an attenuated sensitivity to moving stimuli. By choosing a constant suprathreshold contrast level (five times detection threshold) for each subject, we normalized our targets to each individual's sensitivity, for patients and control subjects alike. It is generally accepted that velocity discrimination thresholds only depend on contrast for levels at or near detection threshold (Thompson, 1983; Bowne, 1990; Müller and Greenlee, 1994). We, therefore, assume that the contrast level was sufficient to make accurate velocity discriminations (see below).

Velocity discrimination thresholds for sequentially presented stimuli were significantly elevated in the patients with damage to ST cortex, and this effect was more pronounced for the visual field contralateral to the damaged hemisphere (Fig. 5). These discrimination thresholds were also significantly elevated for stimuli presented in the visual field ipsilateral to the damaged hemisphere. It might be argued that antiepileptic medication affects velocity discrimination thresholds, and that such a medication effect could underlie the impaired performance for both hemifields. We tested this possibility by comparing patients who were taking medication at the time of investigation $(n=12)$ to those who were not $(n=11)$. This analysis revealed that the use of antiepileptic medication had no effect on the velocity judgments $[F(1,21)=0.036$, NS], nor did this factor significantly interact with any of the other variables in the ANOVA model. The use of medication also had no effect on contrast sensitivity, which rules out the possibility that it could have had an effect on performance in these perceptual tasks for the present patient sample.

The finding that discrimination thresholds were also elevated for stimuli presented in the hemifield ipsilateral to the damaged cerebral hemisphere rather suggests a genuinely bilateral impairment in the ability of these patients to perform the delayed velocity discrimination task. The bilateral impairment of velocity discrimination performance might point to the involvement of both hemispheres and their callosal connections in the evaluation of stimulus speed. Half of the trials presented to the subjects involved stimuli that were presented in opposite visual fields. Although we could not find a significant interaction between hemifield presentation (left or right) and whether or not the comparison stimulus was presented in the same or opposite visual field, the random location of the second stimulus on each trial could have led to a more global strategy, which would imply

Figure 7. Computed tomographic map of the $z$ score weighted location of the cortical lesions averaged over all 23 patients and the three delayed discrimination conditions. Panel $a$ shows a lateral view of the 10 computed tomographic slices, and panel $b$ shows the topographic distribution of the averaged $z$ scores. Light areas signify the lesion locations that were associated with the most pronounced impairment in velocity discrimination.
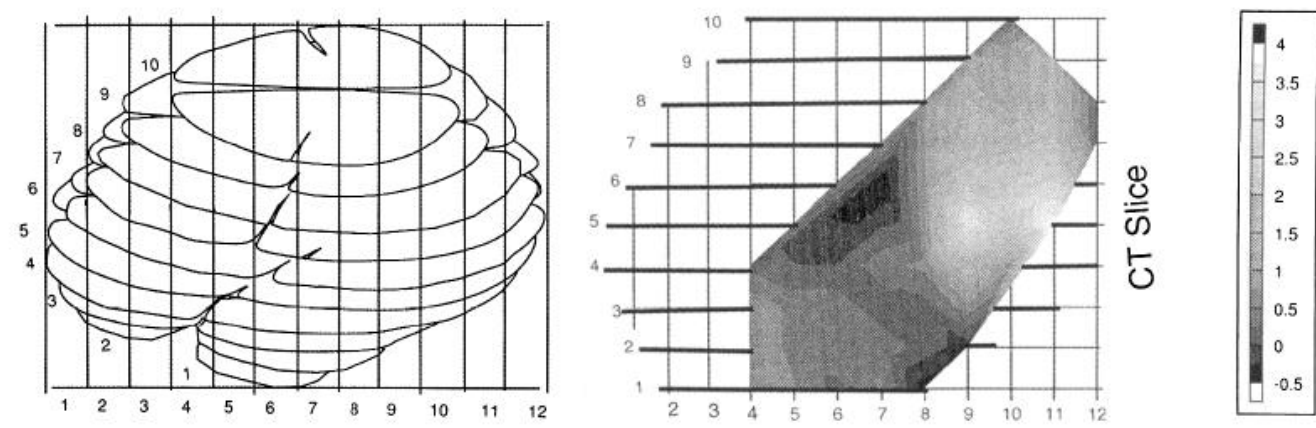
the monitoring of both visual hemifields. It should also be noted that the patients studied here, on average, underwent surgery 2 years prior to the time of study. It is now believed that the adult cortex remains to some extent plastic (Hendry et al., 1990; Gilbert and Wiesel, 1992). It might be interesting to speculate that modification of the callosal connections in the temporal cortex could remediate some of the functional loss imposed by the unilateral lesion. At the same time, such changes could increase the overall neural noise in both hemispheres, thereby reducing the signal-to-noise ratio in the otherwise healthy cortical hemisphere.

Plant et al. (1993) have recently reported three cases in which patients with unilateral damage to cxtrastriatc cortcx cxhibit clevated thresholds for discriminating the direction and speed of eccentrically presented grating patches. The interpretation of their results is complicated, however, by the fact that these patients demonstrated a quadrant anopia, suggesting that the surgical resections were deep enough to affect the fibers in the optic radiation. We have excluded any patients who showed signs of substantial visual field loss, thereby assuring that any impairments in motion perception were not related to loss of primary visual function. The same three patients studied by Plant et al. (1993). only showed elevated speed discrimination thresholds in the visual field contralateral to the lesioned hemisphere. This result conflicts with the present findings, in which deficits were evident in both visual fields. Plant and co-workers studied their patients within the first few months following surgery, whereas our patients were studied, on average, 2 years after surgery. The differences in the results might also be related to the fact that Plant et al. used a short $(0.4 \mathrm{sec})$ ISI, whereas we used ISIs varying from 1 to $10 \mathrm{sec}$. Under their conditions, we would expect to find only small differences in speed discrimination in our patient sample (see Fig. 4).

Velocity discrimination thresholds significantly differed between patient and control groups only for sequentially presented stimuli. An analysis of the differences in the various ISI conditions revealed that the patients did not differ significantly from the control subjects when their judgments were hased on simultaneously presented stimuli. Only if an intervening period of 1 to $10 \mathrm{sec}$ was given in between the reference and test gratings did the patients' performance begin to deteriorate compared to that of the controls, the difference increasing with increasing ISI. This observation suggests that the patients' ability to remember the visual information necessary to perform the velocity discrimination task is impaired, and this impairment is evident even for short delays (Fig. 5). They also suggest that areas in extrastriate cortex might be involved in the short-term storage of the velocity information required to perform the delayed discrimination task.

Lesions in the macaque area MST lead to an impairment in smooth pursuit eye movements (Komatsu and Wurtz, 1988a,b; Newsome et al., 1988). Although the patients and control subjects alike were asked to fixate a point in the center of the dis play, it is possible that the patients might have had more difficulty maintaining fixation over longer intervals. A separate investigation (H. Kimmich, C. Pinow, T. Mergner, and C. H. Lücking, unpublished observations) measured smooth pursuit eye movements in six of the ST patients studied here. They found that the gain of smooth pursuit was reduced by up to $30 \%$. They did not, however, find any signs of nystagmus or fixation problems in these patients. This observation suggests that an eye movements disorder is not related to the elevated speed discrimination thresholds. Difficulties in maintaining fixation would have affected detection thresholds and spatial frequency discrimination thresholds to an equal extent. Since both of these measures were unaffected in the patients, it seems unlikely that disturbed control of eye position would cause the effect on speed discrimination.

We chose to use a spatial and temporal frequency in the medium spatiotemporal frequency range $(1.6$ cycles/degree, $2 \mathrm{~Hz})$ and measured sensitivity and discrimination performance at that and neighboring drift frequencies. Although it has been shown that cells in area MT of the macaque monkey tend to respond more robustly to higher stimulus velocities (Maunsell and van Essen, 1983), a number of methodological aspects led to our decision to use this stimulus range. Pilot work revealed that at higher velocities perceived contrast covaried systematically with stimulus speed. A subset $(n=5)$ of our ST-lesion patients performed the detection and discrimination tasks for stimuli drifting at an average rate of $8 \mathrm{~Hz}\left(5^{\circ} / \mathrm{sec}\right)$. Despite the cues normally available via changes in perceived contrast, the patients were significantly worse than the controls at making velocity judgments at these higher stimulus speeds. As was evident for the main experiments, an impaired discrimination performance was found despite the absence of a difference between the patients and controls with respect to sensitivity to these same stimuli. We conclude from this evidence that the differences shown by the patients are robust and do not depend on the exact stimulus condition we have selected.

Velocity discrimination thresholds for grating stimuli can be as low as $5 \%$ in foveal vision, but they increase with increasing eccentricity (Johnston and Wright, 1985; McKee et al., 1986). The values found for the control subjects in this study are substantially higher than these values. These higher thresholds are related to a number of stimulus parameters, such as the short presentation duration, the low reference speed (see above), the relatively low contrast and the eccentric presentation, as well as the uncertainty of position in the delayed task. The random jitter introduced on a trial-to-trial basis to the refcrence velocity also adds to the stimulus uncertainty, a factor that has been shown to increase detection and discrimination thresholds (Pelli, 1985; Graham, 1989). A further factor that could have influenced performance in the discrimination task is training. Both control subjects and patient performed these psychophysical tasks for the first time, a fact that could have contributed to fairly high discrimination thresholds.

The contrast level of the gratings used in the velocity discrimination task was low, varying from $2 \%$ to $3 \%$, depending on the observer's detection threshold. This low contrast was selected in light of the finding that approximately half of the cells in the macaque extrastriate area MT have a semisaturation constant less than 7\%, and a median exponent of 3.0 (Sclar et al., 1990). In the striate cortex of macaque, these values correspond to $33 \%$ and 2.4, respectively. Such differences would imply that cells in visual areas in the primate extrastriate cortex should saturate at lower contrast levels than those in striate cortex. Studies using positron emission tomography (PET) in subject viewing low contrast stimuli (Miezin et al., 1988) found a peak in regional blood flow in the temporal-parietal-occipital junction area. Our use of moderately low contrast stimuli could be important when searching for differences between brain-damaged patients and controls, since it has been reported that performance requiring the differential velocity perception of moving high-contrast, random dots might be, for the most part, unaltered in such patients (Nawrot et al., 1993). 
Among the 23 patients studied, 11 patients had lesions that were primarily located in or near the border region between the posterior temporal cortex and occipital-parietal junction, whereas the other patients had lesions that were located in the parictal or inferotemporal cortex. We explored the possible effect of the interstimulus interval (ISI) on discrimination thresholds after dividing these patients into three groups based on the location of the cerebral lesion. This region-of-interest analysis revealed a significant effect of ISI on velocity discrimination thresholds in patients with ST lesions (Fig. 6). Velocity discrimination thresholds were only marginally elevated in the patients with inferotemporal damage, and not at all in patients with lateral parietal lesions. As we found a moderately significant effect of age on velocity discrimination thresholds, it might be argued that the age of the ST group could underlie the differences found here. A comparison of the three patient groups yielded, however, no significant differences on mean age. Nor was the age effect more pronounced within the ST group. We conclude that patients with damage in the posterior part of the temporal cortex are impaired in their ability to encode and store stimulus velocity information, irrespective of their age.

The correlation between age and velocity discrimination thresholds was only marginally significant, whereas that between age and contrast sensitivity was more robust. Contrast sensitivity declined by about $1 \mathrm{~dB}$ per decade of life in both patient and control groups for the medium spatio-temporal stimulus range used here. The Weber fraction for velocity discrimination increased by 0.06 per decade of life in the control group and 0.12 per decade in the patients (Table 2). Viewed in this way, a cerebral lesion in extrastriate areas acts to augment the effects of aging on visual memory for stimulus velocity.

\section{The location of the human homolog of the "motion area"}

In Figure 7, we presented the results of a z-transformation of the patients' velocity discrimination thresholds. As is evident in the figure, there is a clearcut peak in the distribution of the $\mathrm{z}$-scores, which suggest that performance is most impaired when the lesion includes the border region between the lateral occipital and temporal cortex (the posterior-inferior part of Brodmann's area 39 , bordering areas 37 and 19). The topographic specificity of the cortical lesions found for the velocity discrimination task support recent attempts to locate a motion area in the human extrastriate cortex. Corbetta et al. (1991) recorded changes in regional blood flow using positron emission tomography in subjects who viewed moving stimuli. When the subjects attended to the speed of the random dot stimuli, these authors found evidence suggesting enhanced neuronal activity in the border region between the inferior parietal lobule bordering the angular gyrus (their Figs. 5 and 6). Using random checkerboard stimuli, other authors (Zeki et al,, 1991; Watson et al., 1993) have reported a similar locus of activity in subjects who passively viewed stimuli in motion. The Talairach coordinates of the peak of the z-transformation maps (Fig. 7) is approximately $16 \mathrm{~mm}$ superior to that reported by Zeki et al. (1991) for site of maximal cerebral blood flow during visual motion stimulation (their Table 2). Considering the inherit lack of resolution in mapping out the effects of postsurgical brain lesions, this correspondence between our results and those of PET studies is remarkable. Together, the results of both earlier studies and the present one suggest that the human homolog of the motion area is located in the temporal-occipital-parietal junction region.

In healthy human observers, velocity information can be stored in visual memory with perfect accuracy for periods up to $30 \mathrm{sec}$ (Magnussen and Greenlee, 1992). These results are replicated by our control group who show no tendency for thresholds to increase when the ISI is lengthened from 1 to $10 \mathrm{sec}$. The perfect storage of stimulus velocity information can be disturbed by introducing a "memory masker" during the retention interval (Magnussen and Greenlee, 1992). Interestingly, the memory masking effect was greatest for maskers differing along the velocity dimension, whereas it was independent of the relative direction of the masker. This form of higher level masking suggests that the information about the different dimensions of the stimulus is retained in separate memory stores. Although we have not yet conducted experiments in patients using memory maskers, the results of such experiments might provide more insight into the origin of the impairment in short-term memory for stimulus velocity evident in the ST patients.

In a recent study, we (Greenlee et al., 1993) found elevated spatial frequency discrimination thresholds for stationary gratings in patients with inferotemporal lobe damage. Interestingly, the inferotemporal lobe patients studied here, some of whom also participated in the earlier study, showed little or no difference in their ability to discriminate gratings moving at different speeds (Fig. 5). Patients with superior temporal lobe damage had considerable difficulty discriminating the speed of the drifting grating, but less trouble in discriminating the spatial frequency of stationary gratings (Fig. 6). This pattern of results suggests that the exact location of an extrastriate cortical lesion determines which aspects of higher level visual processing (underlying discrimination of pattern or motion) will he impaired in these patients. A similar dissociation of function was found in patients with impaired speed discrimination, but who had unaltered spatial frequency discrimination of drifting gratings (Plant and Nakayama, 1993). These findings agree with lesion studies, which have shown that lesions in the area MT and MST in the macaque (Pasternak and Merigan, 1994) and the lateral suprasylvian cortex in the cat (Pasternak et al., 1989) lead to moderate, but long-lasting deficits in speed discrimination of gratings and in direction discrimination of global dot motion.

In summary, we have demonstrated that unilateral damage to the posterior temporal-occipital cortex is associated with a deficit in the discrimination of stimulus velocity. There were no differences between the patients and control subjects with respect to contrast sensitivity for these stimuli. Velocity discrimination thresholds significantly increased with increasing interstimulus interval in these patients. This finding suggests that not only the primary processing of motion is disturbed, but also the shortterm storage of velocity information. Finally, we have shown that a subsample of patients, who showed elevated velocity discrimination thresholds, could perform spatial frequency discrimination of stationary gratings with a similar precision as that done by the control subjects. We conclude that our findings support the idea that there is an area in the human temporal-occipital cortex specialized for the analysis of stimulus velocity.

\section{References}

Albright TD (1984) Direction and orientation selectivity of neurons in visual area MT of the macaque. J Neurophysiol 52:1106-1130.

Albright TD (1992) Form-cue invariant motion processing in primate visual cortex. Science 255:1141-1143.

Boussaoud D, Ungerleider LG, Desimone R (1990) Pathways for motion analysis: cortical connections of the medial superior temporal and fundus of the superior temporal visual areas in the macaque. $J$ Comp Neurol 296:462-495. 
Bowne SF (1990) Contrast discrimination cannot explain spatial frequency, orientation or temporal frequency discrimination. Vision Res 30:449-461.

Brandalise BB, Gottsdanker RM (1959) The difference threshold of the magnitude of visual velocity. J Exp Psychol 57:83-88.

Corbetta M, Miezin FM, Dobmeyer S, Shulman GL, Petersen SE (1991) Selective and divided attention during visual discriminations of shape, color and speed: functional anatomy by positron emission tomography. J Neurosci 11:2383-2402.

Gilbert CD, Wiesel TN (1992) Receptive fields dynamics in adult primary visual cortex. Nature 356:150-152.

Graham N (1989) Visual pattern analyzers. New York: Oxford UP.

Greenlee MW, Rischewski J, Mergner T, Seeger W (1993) Delayed pattern discrimination in patients with unilateral temporal lobe damage. J Neurosci 13:2565-2574.

Hendry SHC, Fuchs J, deBias AL, Jones EG (1990) Distribution and plasticity of immunocytochemically localized GABAa receptors in adult monkey visual cortex. J Neurosci 10:2438-2450

Johnston A, Wright MJ (1985) Lower thresholds of motion for gratings as a function of eccentricity and contrast. Vision Res 25:179-185.

Komatsu H, Wurtz RT (1988a) Relation of cortical areas MT and MST to pursuit eye movements. I. Localization and visual properties of neurons. J Neurophysiol 60:580-603.

Komatsu H, Wurtz RT (1988b) Relation of cortical areas MT and MST to pursuit eye movements. III. Interaction with full-field visual stimulation. J Neurophysiol 60:621-644.

Kwong KK, Stern CE, Baker JR et al. (1993) Localization of visual functions and VEP signals with functional MRI. Invest Ophthalmol Vis Sci [Suppl] 34:813.

Lieberman H, Pentland AP (1982) Microcomputer-based estimation of psychophysical thresholds: the best PEST. Behav Res Methods Instr Comput 14:21-25.

Livingston MS, Hubel DH (1987) Psychophysical evidence for separate channels for the perception of form, color, movement and depth. J Neurophysiol 7:3416-3468.

Livingstone M, Hubel D (1988) Segregation of form, color, movement, and depth: anatomy, physiology, and perception. Science 240:740749.

Magnussen S, Greenlee MW (1992) Retention and disruption of motion information in visual short-term memory. J Exp Psychol [Learn Mem] 18:151-156.

Magnussen S, Greenlee MW, Asplund R, Dyrnes S (1990) Perfect visual short-term memory for periodic patterns. Eur J Cognit Psychol 2:345-362.

Magnussen S, Greenlee MW, Asplund R, Dyrnes S (1991) Stimulusspecific mechanisms of visual short-term memory. Vision Res 31: 1213-1219.

Magnussen S, Greenlee MW, Thomas JP (1995) Parallel processing in visual short-term memory. J Exp Psychol (Hum Percept), in press.

Mandriota FJ, Mintz DE, Notterman JM (1962) Visual velocity discrimination: effects of spatial and temporal cues. Science 138:437438.

Maunsell JHR, van Essen DC (1983) Functional properties of neurons in the middle temporal visual area of the macaque: I. Selectivity for stimulus, direction, speed, and orientation. J Neurophysiol 49:11271147.

Maunsell JHR, Nealey TA, De Priest D (19.90) Magnocellular and parvocellular contributions to responses in the middle temporal visual area (MT) of the macaque monkey. J Neurosci 10:3323-3334.

McKee SP (1981) A local mechanism for differential velocity detection. Vision Res 21:491-500.

McKee SP, Silverman GH, Nakayama K (1986) Precise velocity discrimination despite random variations in temporal frequency and contrast. Vision Res 26:609-619.

Merigan WH, Katz LM, Maunsell JHR (1991) The effects of parvocellular lateral geniculate lesions on the acuity and contrast sensitivity of macaque monkeys. $J$ Neurosci.

Miezin FM, Fox PT, Raichle ME, Allman JM (1988) An extrastriate region in human visual cortex sensitive to low contrast moving dots and high temporal frequencies. Invest Ophthalmol Vis Sci 29:326.

Mikami A, Newsome WT, Wurtz RH (1986a) Motion selectivity in macaque visual cortex. I. Mechanisms of direction and speed selectivity in extrastriate area MT. J Ncurophysiol 55:1308-1327.

Mikami A, Newsome WT, Wurtz RT (1986b) Motion selectivity in macaque visual cortex: II. Spatiotemporal range of directional interactions in MT and V1. J Neurophysiol 55:1328-1351.

Milner B (1971) Interhemispheric differences in the localisation of psychological processes in man. Br Med Bull 27:272-277.

Müller R, Greenlee MW (1994) Effect of contrast and adaptation on the perception of the direction and speed of drifting gratings. Vision Res 34:2071-2092

Nadjmi M, Piepgrass U, Vogelsang H (1991) Kranielle Computertomographie. Stuttgart: Thieme.

Nawrot M, Rizzo M, Damasio H (1993) Motion perception in humans with focal cerebral lesions. Investigat Ophthalmol Vis Sci [Suppl] 34: 1231.

Newcombe F, Ratcliff G, Damasio H (1987) Dissociable visual and spatial impairments following right posterior cerebral lesions: clinical, neuropsychological and anatomical evidence. Neuropsychologia 25:149-161.

Newsome WT, Paré EB (1988) A selective impairment of motion perception following lesions of the middle temporal visual area (MT). J Neurosci 8:2201-2211.

Newsome WT, Wurtz DH, Dürsteler MR, Mikami A (1985) Deficits in visual motion processing following ibotenic acid lesions of the middle temporal visual area of the macaque monkey. J Neurosci 5:825840.

Newsome WT, Mikami A, Wurtz RT (1986) Motion selectivity in macaque visual cortex. III. Psychophysics and physiology of apparent motion. J Neurophysiol 55:1340-1351.

Newsome WT, Wurtz RH, Komatsu H (1988) Relation of cortical areas MT and MST to pursuit eye movements. II. Differentiation of retinal from extraretinal inputs. J Neurophysiol 60:604-620.

Notterman JN, Page DE (1957) Weber's law and the difference threshold for the velocity of a seen object. Science 126:652.

Orban GA, de Wolf J, Maes H (1984) Factors influencing velocity coding in the human visual system. Vision Res 24:33-39.

Pasternak T, Merigan WH (1994) Motion perception following lesions in the superior temporal sulcus in the monkey. Cereb Cortex 4: in press.

Pasternak T, Leinen LJ, Maunsell JHR (1989) Deficits in speed discrimination following lesions of the lateral suprasylvian cortex in the cat. Vis Neurosci 3:365-375.

Pelli DG (1985) Uncertainty effects explain many aspects of visual contrast detection and discrimination. J Opt Soc Am [A] 2:15081531.

Plant GT, Nakayama K (1993) The characteristics of residual motion perception in the hemifield contralateral to lateral occipital lesions in humans. Brain 116:1337-1353.

Plant GT, Laxer KD, Barbaro NM, Schiffman JS, Nakayama K (1993) Impaired visual motion perception in the contralateral hemifield following unilateral posterior cerebral lesions in humans. Brain 116: 1303-1335.

Robson JG (1966) Spatial and temporal contrast-sensitivity functions of the visual system. J Opt Soc Am 56:1141-1142.

Rodman HR, Albright TD (1987) Coding of visual stimulus velocity in area MT of the macaque. Vision Res 27:2035-2048.

Saito H, Masao Y, Tanaka K, Hikosaka K, Fukada Y, Iwai E (1986) Integration of direction signals of image motion in the superior temporal sulcus of the macaque monkey. J Neurosci 6:145-157.

Schiller PH, Logothetis NK, Charles ER (1990) Functions of coloropponent and broad band-channels of the visual system. Nature 343: $68-70$.

Sclar G, Maunsell JHR, Lennie P (1990) Coding of image contrast in central visual pathways of the macaque monkey. Vision Res $30: 1-$ 10.

Seeger W (1978) Atlas of topographical anatomy of the brain and surrounding structures. Wien: Springer.

Seltzer B, Pandya DN (1978) Afferent cortical connections and architectonics of the superior temporal sulcus and surrounding cortex in the Rhesus monkey. Brain Res 149:1-24.

Smirni P, Villardita C, Zappala G (1983) Influence of different paths on spatial memory. Performance in the block tapping test. J Clin Neuropsychol 5:355-359.

Snowden RJ, Treue S, Andersen RA (1992) The response of neurons in areas V1 and MT of the alert rhesus monkey to moving random dot patterns. Exp Brain Res 88:389-400.

Spatz WB (1977) Topographically organized reciporal connections be- 
tween areas 17 and MT (visual area of the superior temporal sulcus) in the marmoset Callithrix jacchus. Exp Brain Res 27:559-572.

Spatz WB, Tigges JB (1972) Experimental-anatomical studies on the "middle temporal visual area" (MT) in primates: I. Efferent corticocortical connections in the marmoset Callithrix jacchus. J Comp Neurol 146:451-464.

Stone LS, Thompson P (1992) Human speed perception is contrast dependent. Vision Res 32:1535-1549.

Talairach J, Tournoux P (1988) Co-planar stereotaxic atlas of the human brain. Stuttgart: Thiema.

Tanaka K, Saito HA (1989) Analysis of motion of the visual field by direction, expansion/contraction and rotation cells clustered in the dorsal part of MST of the macaque. J Neurophysiol 62:626-641.

Tanaka K, Hikosaka K, Saito H, Yukie M, Fukada Y, Iwai E (1986) Analysis of local and wide-field movements in the superior temporal visual areas of the macque monkey. J Neurosci 6:134-144.

Tanaka K, Fukada Y, Saito HA (1989) Underlying mechanisms of the response specificity of expansion/contraction and rotation cells in the dorsal part of the medial superior temporal area of the macaque monkey. J Neurophysiol 62:642-656.

Thompson P (1982) Perceived rate of movement depends on contrast. Vision Res 22:377-380.

Thompson P (1983) Discrimination of moving gratings at and above detection threshold. Vision Res 23:1533-1538.

Tootell RGH, Kwong KK, Belliveau JW, et al. (1993) Mapping human visual cortex: evidence from functional MR and histology. Investi Ophthalmol Vis Sci [Suppl] 34:813.

Ungerleider LG, Desimone R (1986) Projections to the superior tem- poral sulcus from the central and peripheral representations of $\mathrm{V} 1$ and V2. J Comp Neurol 248:147-163.

Ungerleider LG, Mishkin M (1982) Two cortical visual systems. In: Analysis of visual behavior (Ingle J, Goodale MA, Mansfield RJW, eds), pp 549-586. Cambridge, MA: MIT PIess.

Vaina LM (1989) Selective impairment of visual motion interpretation following lesions of the right occipito-parietal area in humans. Biol Cybern 61:347-359.

Watson JDG, Myers R, Frackowiak RSJ, Hajnal JV, Woods RP, Mazziotta JC, Shipp S, Zeki S (1993) Area V5 of the human brain: evidence from a combined study using positron emission tomography and magnetic resonance imaging. Cereb Cortex 3:79-84.

Wechsler D (1987) WMS-R: Wechsler memory scale-revised manual. San Antonio, TX: The Psychological Corporation, Harcourt Brace Jovanovich

Zeki SM (1971) Cortical projections from two prestriate areas in the monkey. Brain Res 34:19-35.

Zeki S (1978) Uniformity and diversity of structure and function in rhesus monkey prestriate visual cortex. J Physiol (Lond) 277:273290.

Zeki S, Watson JDG, Lueck CJ, Friston KJ, Kennard C, Frackowiak RSJ (1991) A direct demonstration of functional specialization in human visual cortex. J Neurosci 11:641-649.

Zihl J, von Cramon D, Mai N (1983) Selective disturbance of movement vision after bilateral brain damage. Brain 106:313-340.

Zihl J, von Cramon D, Mai N, Schmid C (1991) Disturbance of movement vision after bilateral posterior brain damage: further evidence and follow up observations. Brain 114:2235-2252. 